\title{
QUALIDADE DO EMPREGO NAS TELECOMUNICAÇÕES PÓS-PRIVATIZAÇÃO
}

\author{
Daniel Gustavo Mocelin ${ }^{*}$
}

Este artigo propõe uma reflexão sobre qualidade do emprego nas atividades de telecomunicações que, no Brasil, passaram por recente processo de reestruturação, seguido de privatização, caracterizando um novo cenário empresarial, marcado por inovações tecnológicas, expansão comercial e competição de mercado.

Em 1997, a Organização Internacional do Trabalho divulgou um informe sobre os empregos gerados na década de 1990 e destacou que a qualidade do emprego não se refere apenas aos níveis de produtividade e salários, mas abarca também outos aspectos sobre as condições de emprego dos trabalhadores, destacando-se o tipo de relação de trabalho entre o trabalhador e o empregador, a duração da jornada de trabalho, a proteção social vinculada ao emprego e o exercício de direitos laborais fundamentais. Essa abordagem protela uma preocupação em considerar a qualidade do emprego sob uma perspectiva social, não apenas

* Doutorando do Programa de Pós-graduação em Sociologia da Universidade Federal do Rio Grande do Sul. Av. Bento Gonçalves, 9.500. Campus do Vale, IFCH, Prédio 43311 Sala 103, Bairro Agronomia. Cep: 90501900 Porto Alegre-RS - Brasil. dmocelin@terra.com.br econômica, a fim de subsidiar políticas sociais de emprego. Destaca-se que a discussão sobre qualidade do emprego estava concentrada no campo da economia, privilegiando aspectos como a produtividade do trabalho e, quando tratava sobre os trabalhadores, ficava restrita à análise do nível salarial ou status contratual.

O estudo de Barros e Mendonça (1995) enriquece a discussão conceitual sobre o tema em foco, ao sugerir que a "qualidade do emprego" seria a qualidade percebida pelos trabalhadores, cujo indicador de maior importância seria o salário e que a "qualidade intrínseca do posto de trabalho" teria a produtividade como principal medida. Sobre isso, Moreira Cardoso (2000, p. 133) afirmou que a teoria econômica e o discurso empresarial costumam hierarquizar os postos de trabalho por sua produtividade: postos de melhor qualidade são os que geram maior quantidade de produto, enquanto que, do ponto de vista do trabalhador, a qualidade pode estar associada a uma síndrome de determinantes, dentre os quais a produtividade não seria o mais relevante, podendo mesmo implicar maior ritmo de trabalho e, portanto, pior 
qualidade. Contudo, essa perspectiva sobre a produtividade, que é correta em alguns setores econômicos, pode ser diferenciada, principalmente se maior produtividade significar retorno para os trabalhadores. Em alguns casos, a maior produtividade dos setores econômicos proporciona maiores salários em relação ao contexto geral do mercado de trabalho ou participação dos trabalhadores nos lucros e resultados das empresas.

Ao se considerarem as questões abordadas na discussão sobre qualidade do emprego, pode-se identificar que muitas delas são bastante discutidas pela sociologia, tais como a organização do trabalho, as condições de emprego, o mercado de trabalho, as relações de trabalho. Independentemente de uma perspectiva de análise objetiva ou subjetiva, o debate gira em torno de aspectos convergentes, mas o que chama a atenção é a sua complexidade, em razão do caráter multidimensional que assume a noção de qualidade do emprego. Em termos sociológicos, a qualidade do emprego pode ser entendida como a combinação de um conjunto de atributos relacionados aos empregos que expressam condições de bemestar individual e social dos empregados, revelando as propriedades desses empregos em termos de suportes sociais para os trabalhadores que os ocupam. Como indicadores, poderiam ser apontados: o tipo de contrato de trabalho, com destaque para aqueles por tempo indeterminado; o grau de remuneração, especialmente aquelas superiores a um mínimo estabelecido; a escolaridade dos trabalhadores, em que o maior grau de instrução tende a indicar maior exigência do emprego e, portanto, uma melhor remuneração; o tamanho da jornada de trabalho, em que não se observe nem uma jornada excessiva nem uma jornada demasiado curta que impacte negativamente a remuneração do trabalho. A qualidade do emprego implica, ainda, a diferenciação entre empregos em mercados de trabalho segmentados e diversificados, o que expressa propriedades dos empregos que permitem diferenciá-los. A qualidade do emprego tambémé impactada por determinantes externos aos empregos, que variam segundo particularidades do contexto, das condições econômicas e da natureza das atividades econômicas.
No contexto de importantes mudanças no mundo do trabalho, competitividade e produtividade tornam-se elementos decisivos para os setores que lidam com tecnologia avançada. A problemática em pauta, neste ensaio, é como a qualidade do emprego se expressa nos ambientes empresariais em que a tecnologia, a produtividade e a competitividade são características recorrentes. $\mathrm{O}$ argumento central do presente estudo sustenta que, mesmo mantendo como indicadores da qualidade do emprego aqueles baseados nos padrões da sociedade industrial, o comportamento dos indicadores difere dos padrões do passado frente à realidade do trabalho em que há diferenciação organizacional e freqüente evolução tecnológica, como no caso das telecomunicações. No contexto diferenciado desse setor, o distinto comportamento dos indicadores não pode ser tomado a priori como uma expressão negativa ou positiva da qualidade do emprego. No contexto setorial de mudança tecnológica, lidar com exigências de inovação e competitividade implica que as empresas disponham de empregados que possam acompanhar as evoluções do mercado. Portanto, os trabalhadores empregados nessas empresas são de tipo diferente dos empregados sob o modelo fordista, em que a produção era massificada e homogeneizada, demandando, habilidades em tarefas específicas e rotineiras. A idéia de qualidade do emprego possui princípios que são comuns às diferentes abordagens, sendo importante considerar que a evolução do tema não consiste em ruptura com as discussões tradicionais, mas na abertura para novas proposições e lógicas de avaliação diferenciadas, condizentes com a nova realidade do trabalho e com a nova realidade social. Talvez um dos aspectos mais pertinentes seja que essa discussão acompanhe as mudanças na economia e na sociedade e no perfil das empresas e dos setores econômicos e dos próprios trabalhadores.

Como afirma Aierbe (2004, p. 8), o debate sobre a qualidade do emprego é, em todo caso, um debate dinâmico e aberto. Para Tokman (1999) as questões analisadas apontam para a insuficiência do conhecimento sobre qualidade do emprego: tra- 
ta-se de examinar questões complexas, difíceis de medir ou estimar, e que são relativas a culturas e graus de desenvolvimento. Além disso, como sugere Abrantes (2005, p. 21), a diversidade de perspectivas sobre a qualidade do emprego é enriquecedora face à sua noção mais restrita e tradicional, com base em parâmetros que, sem perderem importância, são acompanhados pela análise do contexto externo aos empregos.

Fato conhecido, nos últimos quinze anos, o setor de telecomunicações sofreu transformações em conseqüência de um processo global de reestruturação, ${ }^{1}$ em que foram importantes as inovações tecnológicas, a expansão comercial dessas atividades e o papel infra-estrutural que assumiram no contexto da globalização e da economia internacionalizada, aspectos que produziram efeitos importantes não apenas sobre a configuração mas também sobre a situação do emprego neste setor. Frente ao novo perfil das telecomunicações no Brasil, perguntamos qual a situação da qualidade do emprego neste setor quase uma década após a sua privatização. Os resultados apresentados provêm de uma abordagem longitudinal sobre a evolução das condições de emprego nas telecomunicações no período entre 1994 e 2004 e de uma análise comparativa entre as condições de emprego nas telecomunicações e no contexto mais amplo em que está inserida. A intenção foi a de estabelecer algumas reflexões sobre a qualidade do emprego para contextos econômicos mais avançados. Para isso, são analisados alguns aspectos concernentes à qualidade do emprego e que expressam suportes sociais para os empregados, tais como remuneração, tempo de emprego, jornada de trabalho, tipo de contrato de trabalho, escolarização dos empregados e inserção de mulheres. Os resultados para o setor foram comparados com o seu contexto mais amplo, o mercado de trabalho do setor de serviços e o mercado de trabalho do Brasil

${ }^{1}$ Estudos já documentaram vastamente a reestruturação do setor de telecomunicações. Sobre isso, ver: Katz (1997), Gordinho (1997), Walter (1998), Larangeira (1998, 2003, 2004a, 2004b), Ruduit Garcia (2004), Curtinaz da Silva (2003), Melo e Gutierrez (1998), Wohlers (1999), Dores (1999), Pires (1999), Novaes (2000), Neves (2002), Galina (2003), Büchner e Rückert (2004), Balbontín (2005), Mocelin e Corrêa (2003), Guimarães (2006), Mocelin (2005, 2006). em seu conjunto. A análise da situação do emprego na atividade de telecomunicações ${ }^{2}$ baseia-se nos dados disponíveis na Relação Anual de Informações Sociais (RAIS) do Ministério do Trabalho e Emprego do Brasil (MTE). A análise do contexto das telecomunicações baseia-se em estudos anteriores e em informações provenientes da Agência Nacional de Telecomunicações, responsável pela regulamentação desse setor no país, bem como em materiais obtidos em organizações e sites especializados.

No Brasil, a expansão das telecomunicações foi provocada não só pela demanda econômica e social pelos novos serviços, mas especialmente por mudanças tecnológicas e políticas, as quais decorreram da reestruturação do setor nos anos 1990 e impulsionaram a constituição de um novo cenário organizacional e de emprego bastante distinto do que vigorou até o final dos anos 1980 e o início dos anos 1990. As mudanças tecnológicas referemse ao desenvolvimento e à introdução de novas tecnologias que proporcionaram o desenvolvimento e exploração comercial de novos produtos e serviços, como a telefonia móvel celular, a televisão por cabo e a internet, às quais agregaram diversos outros serviços e a convergência de serviços. As mudanças políticas, por sua vez, incluíram processos de desregulamentação, privatização e liberalização, os quais tiveram repercussão sobre a formação de um ambiente competitivo ${ }^{3}$ de atuação das empresas. Segundo alguns estudos, o sistema público de telecomunicações existente no Brasil até então teria dificuldades de efetuar os investimentos necessários para suportar a velocidade e a natureza das mudanças exigidas para a atualização do setor ao grau dos padrões internacionais.

No Brasil, até 1994, o setor de telecomuni-

2 Segundo a Classificação Nacional de Atividades Econômicas (CNAE, 1995), a atividade de telecomunicações refere-se aos empregos que estão alocados no setor de serviços; destaca-se que o setor de telecomunicações ainda incluiria as atividades do setor que são alocadas na construção civil (obras em telecomunicações) e na indústria (fabricação de equipamentos de telecomunicações).

${ }^{3} \mathrm{O}$ ambiente competitivo do setor foi idealizado pelo Governo brasileiro e é reflexo da Lei Geral de Telecomunicações (Lei No 9.472/1997). Convém destacar que a competição foi virtuosa apenas no caso da telefonia móvel celular e entre essa e a telefonia fixa. 
cações estava constituído por empresas estatais, embora com capital misto, organizadas em regime de monopólio, que operavam em âmbito nacional e produziam exclusivamente telefonia fixa como serviços de utilidade pública. Com as mudanças na base tecnológica e o fim do monopólio estatal, ${ }^{4}$ entraram no mercado diversas possibilidades de novos produtos e serviços, abrindo-se a perspectiva para a exploração comercial segundo a concorrência e o atendimento às novas demandas, cada vez mais heterogêneas. Dez anos depois, o setor de telecomunicações constitui-se por empresas de capital privado com cultura e filosofia orientadas para o mercado, privilegiando a produtividade, a eficiência, a qualidade do serviço e a lucratividade.

O novo perfil do setor de telecomunicações teve significativa incidência sobre o emprego no setor, mas o crescimento do setor e a diversificação dos serviços também tiveram repercussões importantes nesse sentido. Em 1990, existiam 10 milhões de acessos telefônicos fixos, equivalentes, em teledensidade, a 7,1 acessos telefônicos para cada 100 habitantes. Em 2005, o número de aces- sos instalados superou os 136 milhões, sendo 50 milhões de acessos fixos e 86 milhões de acessos móveis. Neste contexto, constituiu-se um novo quadro dos empregos, implicando, por um lado, aspectos sobre a quantidade de empregos no setor, e, por outro lado, aspectos qualitativos, condicionando a redefinição das condições de emprego e a renovação do contingente de trabalhadores, agora, com perfil diferenciado daquele das empresas públicas. Devese considerar, portanto, que a expansão desse mercado, especialmente marcada pela inovação tecnológica, produziu efeitos sobre o emprego, especialmente na geração de emprego mais qualificado, em detrimento da forte redução de emprego de pouca ou nenhuma qualificação.

Contudo, não seria correto afirmar que as mudanças tecnológicas no setor de telecomunicações implicaram redução do número de empregos nessa atividade, embora uma análise preliminar pudesse apontar nessa direção. Em linhas gerais, ocorreu criação de empregos, mesmo que em níveis modestos. Em alguns casos, houve eliminação de determinadas funções, mas com a criação

Gráfico 1 - Evolução da digitalização nas plantas telefônicas e expansão dos serviços de telecomunicações Brasil, 1994-2005

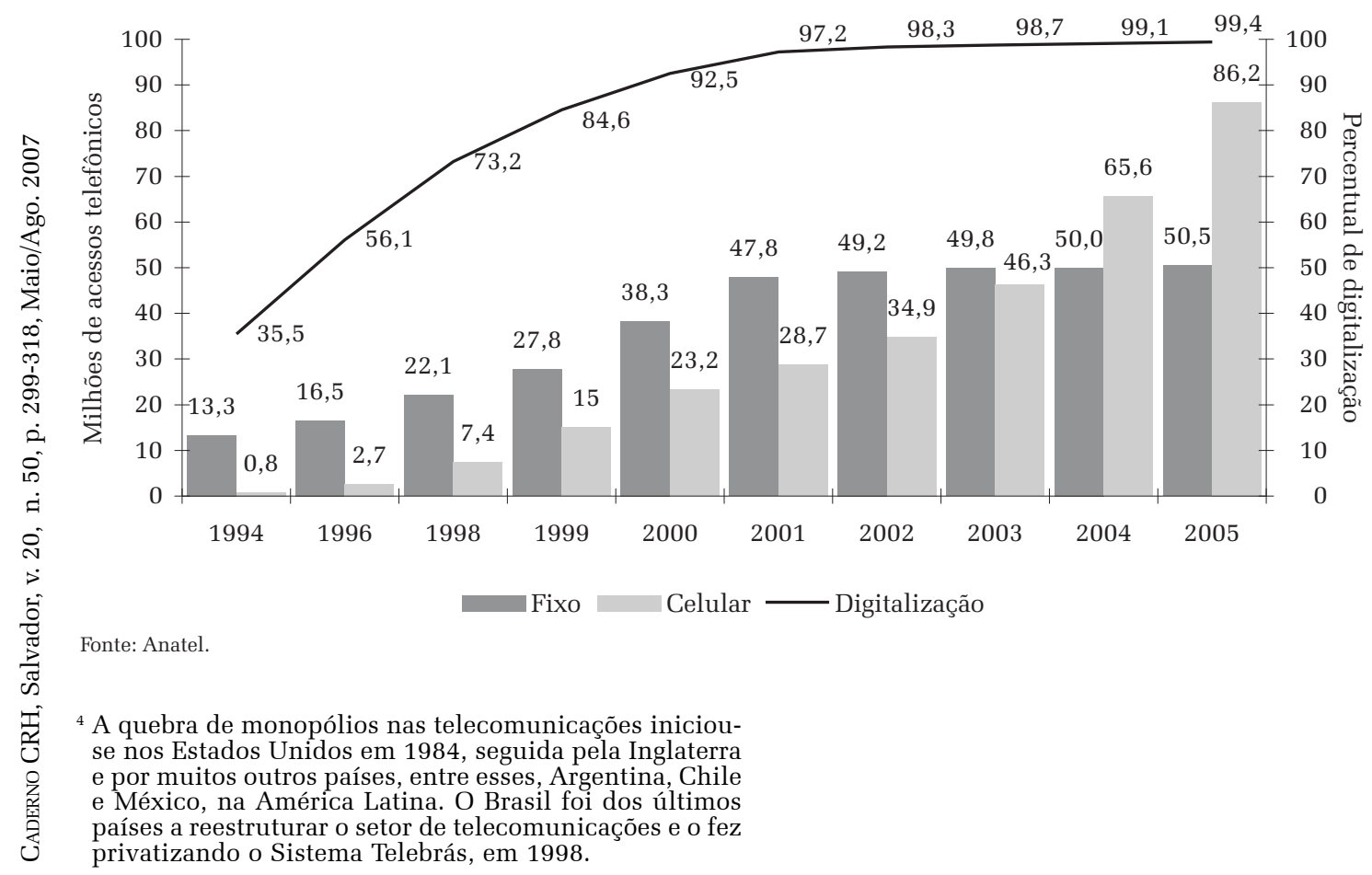


de outras; em outros casos, houve realocação de contingentes de trabalhadores, em conseqüência da formação de novas empresas no setor, da terceirização e das ocupações geradas para gerir uma estrutura organizacional em rede.

Pesquisas realizadas no período logo após a privatização (1999-2001) identificavam que o comportamento do mercado do trabalho, no setor de telecomunicações, demonstrava uma tendência à supressão de empregos nas operadoras e à expansão de trabalho informal, autônomo e em pequenos empreendimentos, observando que tais trabalhadores eram re-inseridos via terceirização e com condições de trabalho precárias. No caso das operadoras de telefonia fixa, houve acentuada redução no número de empregos, porém, em sua maior parte, tal redução ocorreu devido às atividades externalizadas, principalmente os empregos das atividades de manutenção e instalação de terminais e redes de telefonia, empregos de baixa qualificação, que demandavam trabalhadores com baixo grau de escolaridade. Em 1997, um ano antes da privatização, as operadoras de telefonia fixa empregavam 80 mil trabalhadores. ${ }^{5}$ Com a privatização, passaram a ser implementados, nas empresas de telecomunicações, procedimentos organizacionais de racionalização e redução de custos, ${ }^{6}$ o que acarretou, naquele momento, o enxugamento desse contingente de trabalho. Em 1999, dois anos depois da privatização, o número de empregados nas operadoras de telefonia fixa foi menor que $50 \mathrm{mil}$, atingindo 20 mil empregos, em 2002, número que se estabilizou a partir de então (Gráfico 2). Porém, quando tomado o setor de telecomunicações em seu conjunto, ${ }^{7}$ observa-se que o número de empregos no setor não sofreu redução semelhante no período entre 1994 e 2004, tendo inclusive se ampliado (Gráfico 3). Nesse período, o número de empregos reduziu-se em 16 mil na atividade de telecomunicações, correspondente ao setor de serviços. Deve-se destacar, ainda, que os dados apresentados não incluem os call centers, empresas criadas para prestar atendimento ao cliente e fazer vendas por telefone, que tiveram grande expansão após a privatização das telecomunicações, gerando muitos empregos nos últimos

Gráfico 2 - Evolução do número de empregos nas empresas operadoras de telefonia fixa Brasil, 1990-2004

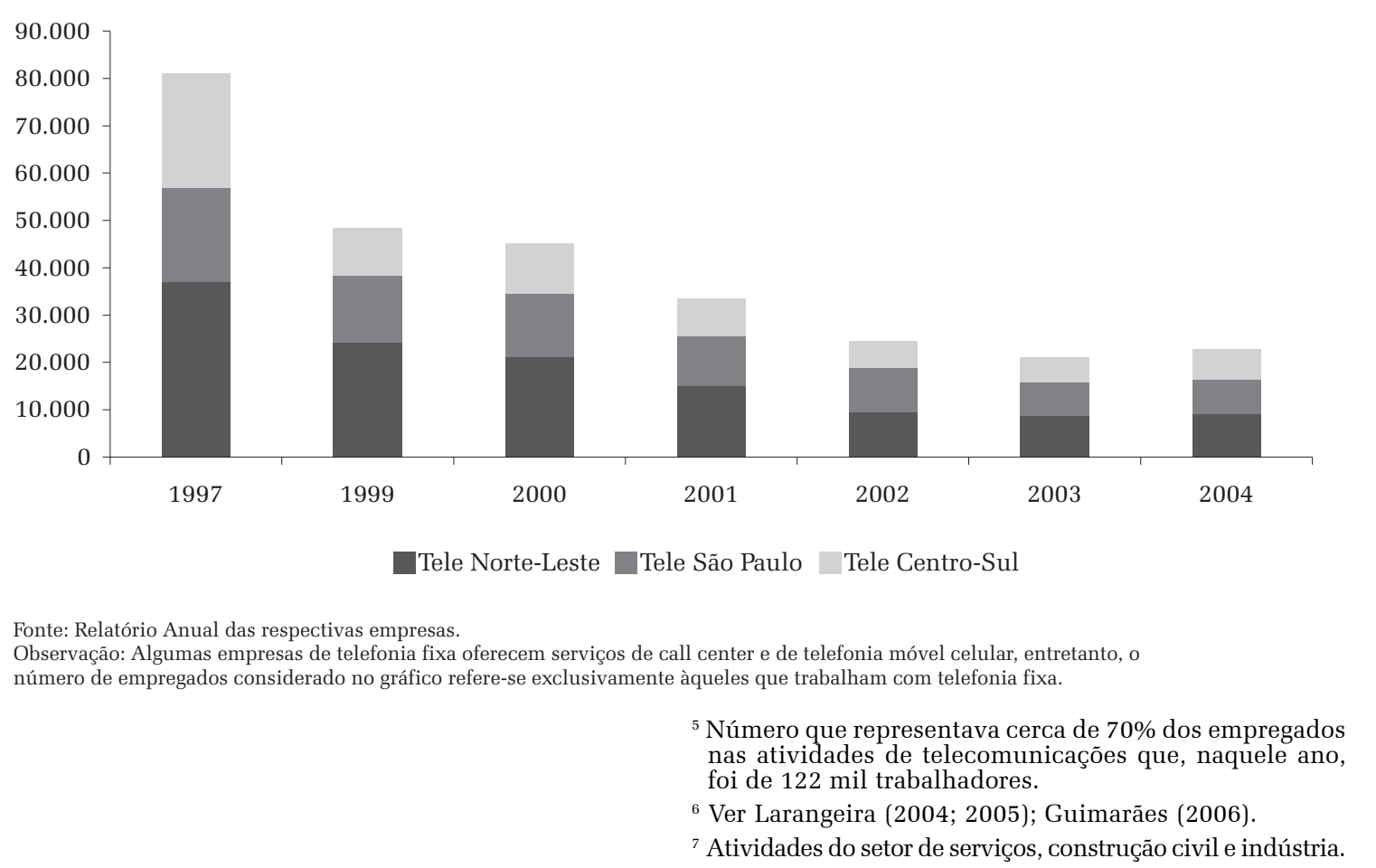


Gráfico 3 - Evolução do número de empregos no setor de telecomunicações Brasil, 1994-2004

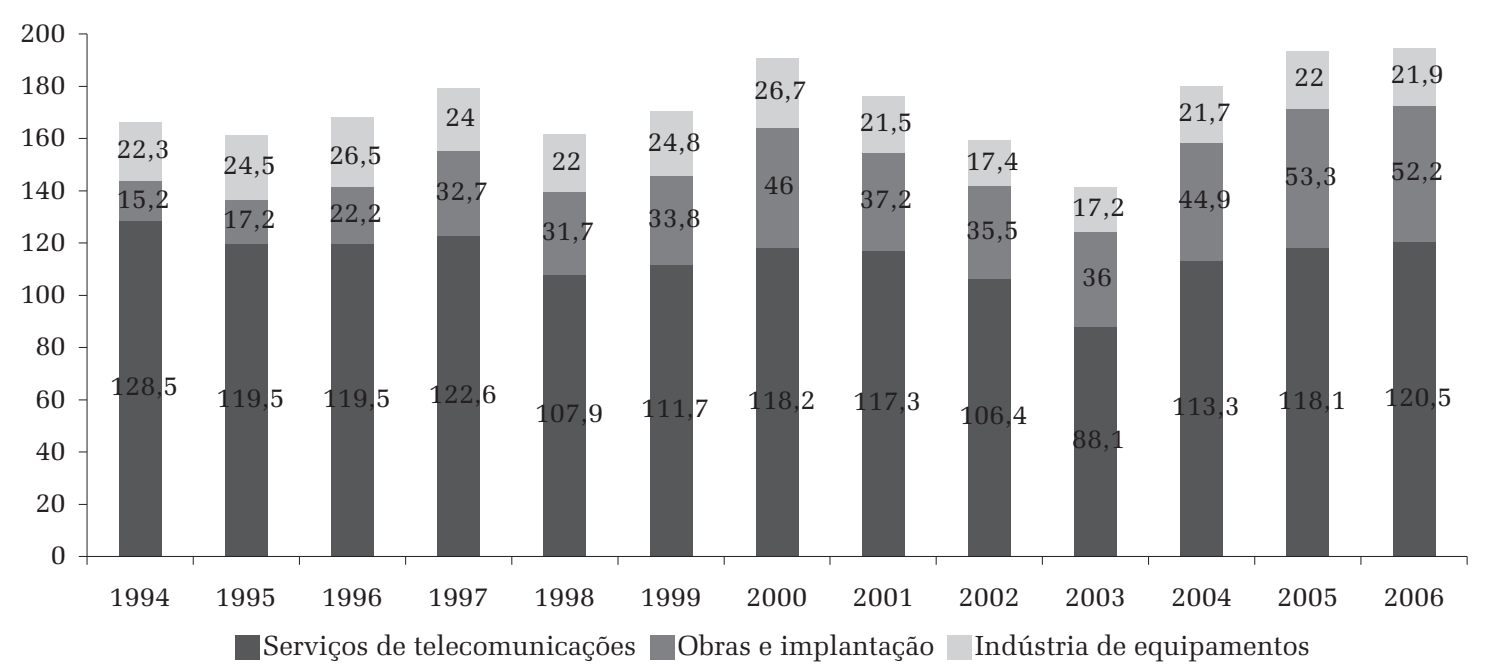

Fonte: Ministério do Trabalho e Emprego, RAIS-Caged.

Nota: Número de vínculos de emprego formais ativos no dia 31 de dezembro do referido ano, declarado pelos respectivos estabelecimentos. Observação: Telecomunicações são atividades alocadas no setor de serviços; obras em telecomunicações são atividades alocadas no setor de construção civil; fabricação de aparelhos telefônicos são atividades alocadas no setor industrial.

anos, uma vez que, na base RAIS, estão alocados em outras atividades, especialmente em serviços prestados às empresas. $^{8}$

Entre 1994 e 1999, ocorre redução no número de trabalhadores na atividade de telecomunicações (serviços) e aumento no número de trabalhadores na atividade definida como obras em telecomunicações (construção civil). Nesse período, haveria uma "preparação para a privatização", expressa pelos planos de demissão voluntária, com

${ }^{8}$ Se fôssemos incluir os empregos em call centers, o número de empregos deveria ser acrescido de $200 \mathrm{mil}$, como consta na base RAIS para o ano de 2005. sando por um grande processo de expansão e diversificação, com as empresas tendo de cumprir as metas de universalização definidas pela Anatel nos contratos de concessão, o que explicaria o aumento do número de trabalhadores tanto na atividade de telecomunicações (serviços) quanto em obras em telecomunicações (instalação de terminais telefônicos). Mesmo com o grande número de trabalhadores formais entre 1998 e 2003, no auge da expansão do setor, existem relatos que apontam para informalidade elevada nas relações de trabalho, especialmente nas atividades de construção civil, comércio e autônomos, o que implicaria um número ainda maior de empregados. Os estudos realizados nesse período apontaram, inclusive, problemas relativos à intensificação do trabalho e instabilidade. Contudo novas exigências de mercado, detidamente marcadas pela qualidade do serviço, conduziram as empresas a praticamente terminar com a "contratação" informal e incorporar muitos trabalhadores a partir de 2004, considerando que os problemas de qualidade apresentados estavam sendo localizados nas atividades subcontratadas, em muitos casos informais, o que causava queda nos índices de qualidade das operadoras, gerando pesadas multas aplicadas pela Anatel. Esse processo recente teria, inclusive, in- 
corporado parte significativa da oferta de mão-deobra para esse setor. Destaca-se, contudo, que isso ocorre depois de uma fase de enxugamento nas empresas. Entre 2001 e 2003, o número total de trabalhadores começa a reduzir-se, porque o setor passaria a se ajustar, consolidando um contingente de trabalhadores capaz de fornecer suporte estratégico e técnico para a sua nova configuração, considerando-se que o número de empregos cai nas telecomunicações e também nas obras em telecomunicações. A partir de 2004, contudo, ocorre novo incremento no número de empregos nas atividades de telecomunicações e obras em telecomunicações. Deve-se considerar que, enquanto as empresas de telefonia fixa se reestruturavam, as empresas de telefonia móvel e de televisão por cabo estavam a surgir e a iniciar expansão comercial. A retomada no crescimento de empregos, em 2004, está relacionada também à expansão dessas empresas que, em 2003, passaram por processos de fusão para poderem atuar em maior número de regiões, favorecendo a competição. Os altos e baixos do número de empregos na atividade de tele- comunicações, entre 1998 e 2004, e a posterior retomada do crescimento de empregos indicam a grande dinâmica desse mercado de trabalho em termos de quantidade de emprego.

Em termos qualitativos, a constituição do novo quadro de empregos do setor implicou transformações ainda mais evidentes do que em termos quantitativos. As transformações qualitativas foram analisadas em duas dimensões complementares, a saber, as condições de emprego e o perfil dos trabalhadores empregados; tais categorias foram tratadas a partir das atividades de telecomunicações referentes ao setor de serviços. ${ }^{9}$

A remuneração está entre um dos principais indicadores para a caracterização das condições de emprego e qualidade do emprego. O atual quadro de remunerações no setor analisado é bastante distinto do quadro anterior à privatização (Gráfico 4). Historicamente, as atividades de telecomunicações no Brasil se caracterizaram por elevado rendimento para os empregados, principalmente no período de monopólio estatal, quando todos eram funcionários públicos. Em 1994, cerca

\section{Gráfico 4 - Evolução da participação percentual dos empregados no setor de telecomunicações por faixa de remuneração (em salários mínimos) Brasil 1994-2004}

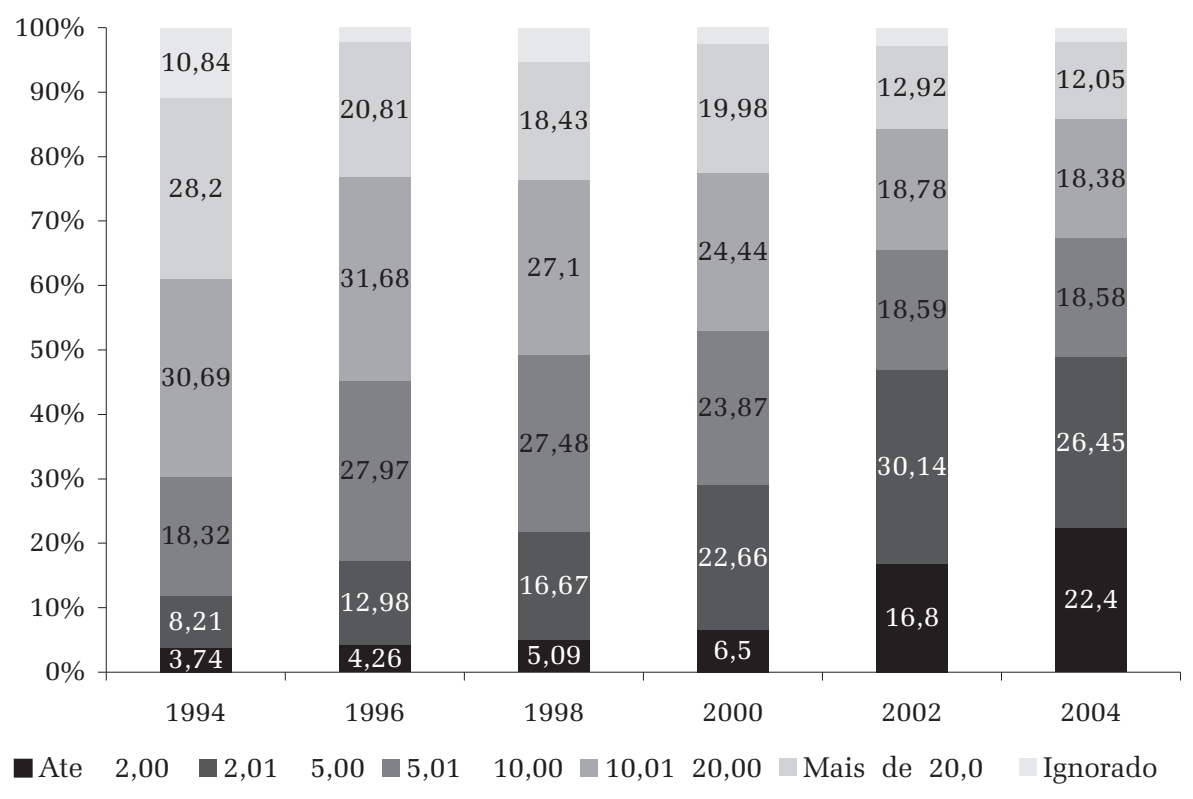

Fonte: Ministério do Trabalho e Emprego, RAIS-Caged. ${ }^{9}$ Priorizou-se a atividade telecomunicações da classifica-
ção da RAIS-Caged. 
de $60 \%$ do contingente de empregados possuía renda superior a dez salários mínimos, sendo que quase 30\% recebiam mais de vinte salários mínimos. ${ }^{10}$ Essa realidade foi modificada gradualmente, como se pode observar na análise da evolução do setor durante a reestruturação e após a privatização. Entre 1994 e 1996, houve a redução dos quadros de remuneração mais elevadas, em razão das aposentadorias incentivadas e dos planos de demissão voluntária nas empresas estatais. Nesse sentido, deve-se considerar que os empregados no setor não passaram a receber menores remunerações, tendo, na verdade, sido aposentados em sua maioria, e novos empregados é que passaram a ter remuneração menor do que a dos antigos funcionários públicos.

Mesmo com redução da concentração de maiores salários no setor, deve-se destacar que grande parte dos empregados do setor continua recebendo remunerações elevadas. Em 2004, cerca de $30 \%$ dos empregados obteve rendimento superior a dez salários mínimos, metade do percentual de dez anos antes, sendo que $12 \%$ recebiam mais de vinte salários mínimos. No recente quadro de remunerações nas telecomunicações (2004), observa-se que cerca de $50 \%$ dos empregados recebiam remuneração superior a cinco salários mínimos; 26,4\% remuneração entre dois e cinco salários mínimos; e 22,4\% remuneração inferior a dois salários mínimos. Essas duas últimas categorias, de rendimento mais baixo, foram as que mais cresceram no período, pois, em 1994, representavam, conjuntamente, pouco mais de $10 \%$ dos empregos. Destaca-se que a categoria de rendimentos de até dois salários mínimos cresceu mais em 2002 e 2004. Porém, mesmo com a redução do número de empregos nas faixas de maiores salários, a atividade de telecomunicações continuou oferecendo rendimentos mais elevados que o mercado de trabalho brasileiro e o mercado de trabalho do setor de serviços. Os Gráficos 5, 6 e $7^{11}$ permitem um contraste sobre a distribuição dos rendimen-

Gráfico 5 - Distribuição percentual por faixas de rendimento - Brasil, 2004
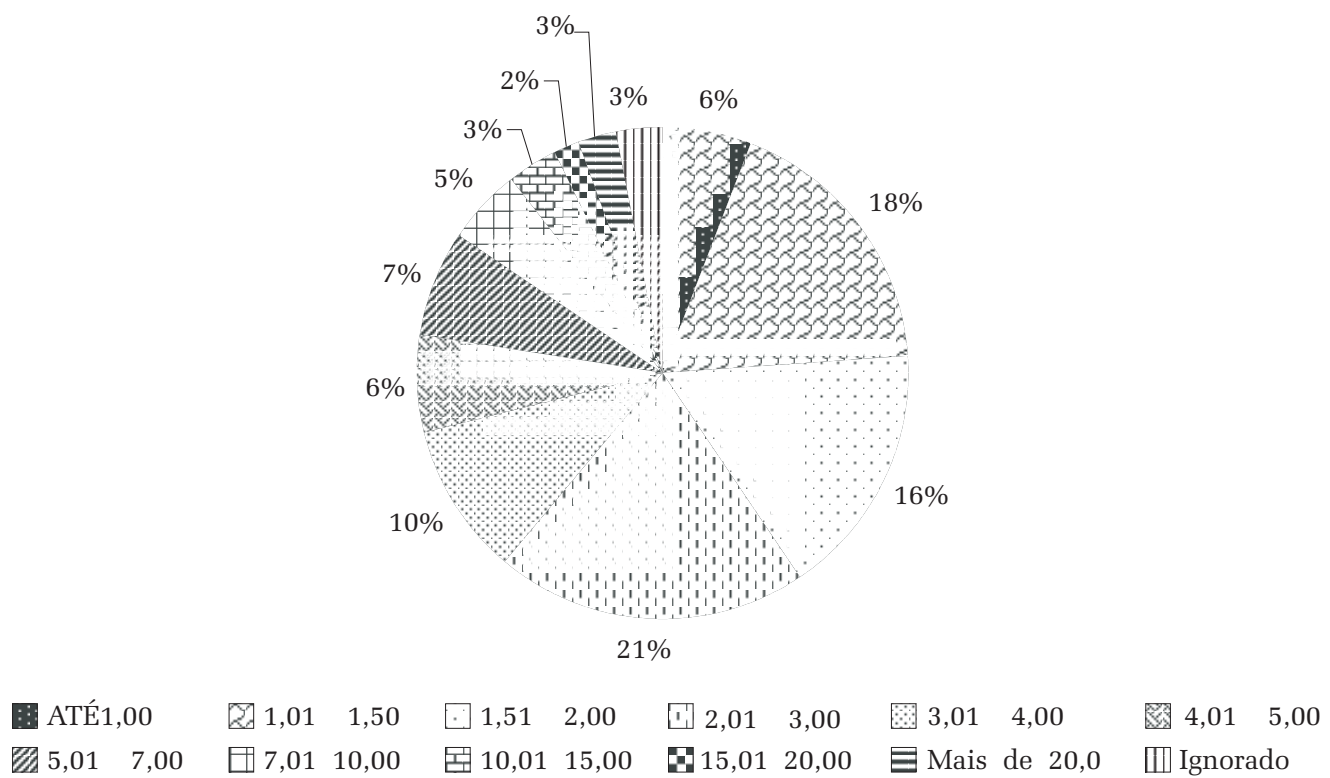

Fonte: Ministério do Trabalho e Emprego, RAIS-Caged.

${ }^{10}$ Deve-se destacar que o valor do salário mínimo teve aumento real significativo desde 1994, o que pode significar uma realocação dos empregados entre as faixas salariais no período e não um efetivo processo de redução drástica das remunerações.

\footnotetext{
${ }^{1}$ Esses gráficos foram segmentados por faixas mais específicas, para se traçar um paralelo com a renda média. A leitura das faixas, nos gráficos, pode ser realizada no sentido horário, a partir das 12 horas, e combinada com a legenda da esquerda para a direita.
} 
Gráfico 6 - Distribuição percentual por faixas de rendimento - Setor de Serviços, 2004

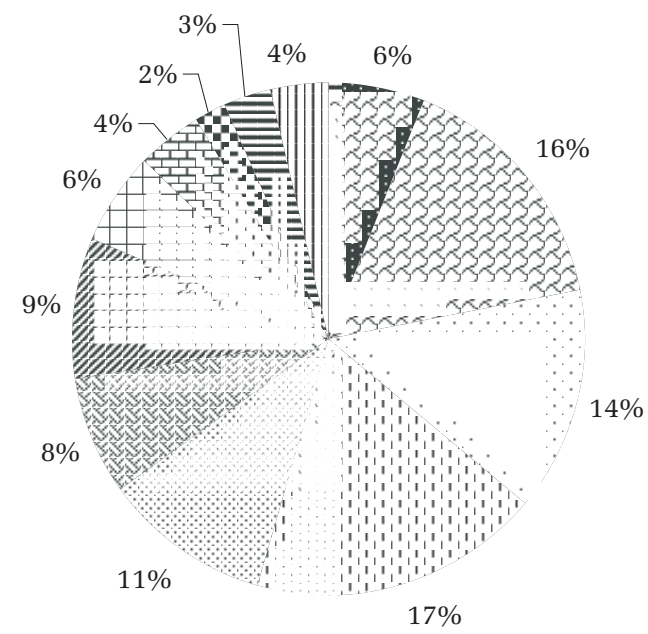

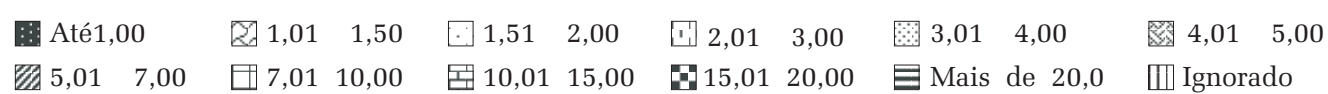

Fonte: Ministério do Trabalho e Emprego, RAIS-Caged.

Gráfico 7 - Distribuição percentual por faixas de rendimento - Telecomunicações, 2004

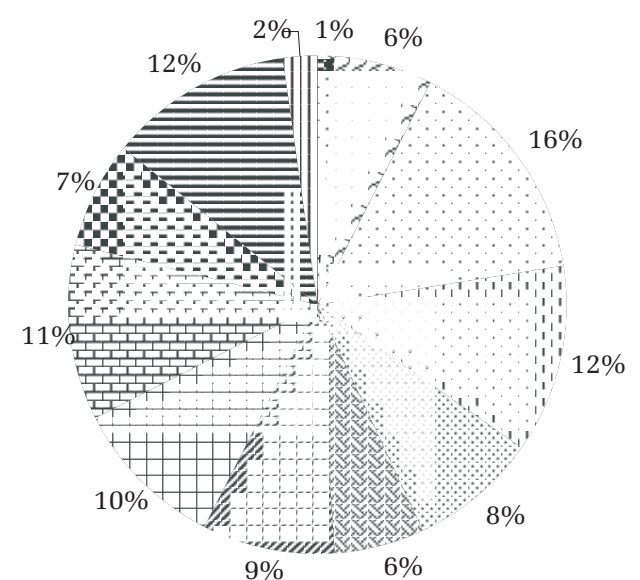

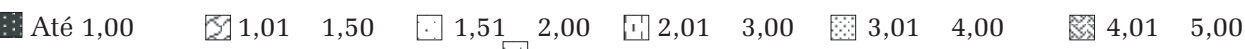

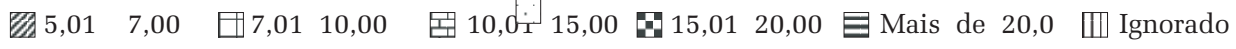

Fonte: Ministério do Trabalho e Emprego, RAIS-Caged.

tos no ano de 2004. Nas telecomunicações, observa-se uma distribuição de rendimentos por faixa salarial mais equilibrada que no mercado de trabalho brasileiro (Gráfico 5) e que no setor de serviços (Gráfico 6), permitindo constatar que as faixas de rendimento mais baixas e as faixas de rendimento mais altas, nessas duas dimensões, são mais concentradas que nas telecomunicações (Gráfico 7).
Um fato importante a se considerar é que, nas telecomunicações, menos de um quarto dos empregados (23\%) recebem menos de dois salários mínimos, enquanto que, no mercado de trabalho formal do Brasil, $40 \%$ dos empregados estão nessa faixa. Ainda no que se refere às remunerações mais baixas, o mercado de trabalho brasileiro caracteriza-se por uma concentração de $61 \%$ dos 
empregos formais com rendimentos de até três salários mínimos mensais (Gráfico 5). Por sua vez, os rendimentos nessa faixa, no setor de serviços, correspondem a 53\% dos empregos (Gráfico 6). No setor de telecomunicações, 37\% dos empregos estão na faixa de rendimento de até três salários mínimos (Gráfico 7). No que se refere às faixas de rendimentos mais altas, o mercado de trabalho formal do Brasil concentra 11\% dos empregos nas faixas de rendimento superiores a dez salários mínimos. Essa situação é seguida pelo setor de serviços, que concentra $13 \%$ dos empregos na mesma faixa. O setor de telecomunicações apresenta 30\% dos empregos com rendimento superior a dez salários mínimos, em 2004.

Considerando o parâmetro das remunerações, pode-se supor que a atividade de telecomunicações parece aproximar-se dos parâmetros de países mais avançados, no que se refere à perspectiva de expansão dos pólos e achatamento do centro, ou seja, observa-se que, em telecomunicações, $37 \%$ dos empregados recebem até três salários mínimos, 51\% recebem acima de cinco salários mínimos e 14\% recebem entre três e cinco salários mínimos. Afirma-se isso, considerando-se que as remunerações podem estabelecer uma tipologia de atividades entre aquelas menos complexas e mais complexas. No caso do mercado de trabalho formal e do setor de serviços, essa perspectiva se demonstra por uma pirâmide de desigualdade salarial, em que a maior parte dos empregos está na base, ou seja, poder-se-ia confirmar a idéia de que a maior parte dos empregos, no mercado de trabalho brasileiro, seria de baixa qualificação, enquanto que, nas telecomunicações, haveria uma distribuição diferenciada.

Em 2004, o salário médio nas atividades de telecomunicações não apenas é mais alto em números absolutos que no mercado de trabalho formal do Brasil e no setor de serviços (Gráfico 8), como o percentual dos empregados que recebem remuneração na média ou acima da média nas telecomunicações é maior que no contexto mais amplo. O rendimento médio nas atividades de telecomunicações foi de $\mathrm{R} \$ 2.269$, equivalente a 8,7 salários mínimos do período, ${ }^{12}$ indicando que $42 \%$ dos empregados da atividade de telecomunicações recebiam remuneração equivalente ou superior ao

Gráfico 8 - Remuneração média individual -

Brasil, Setor de Serviços e Telecomunicações, 2004

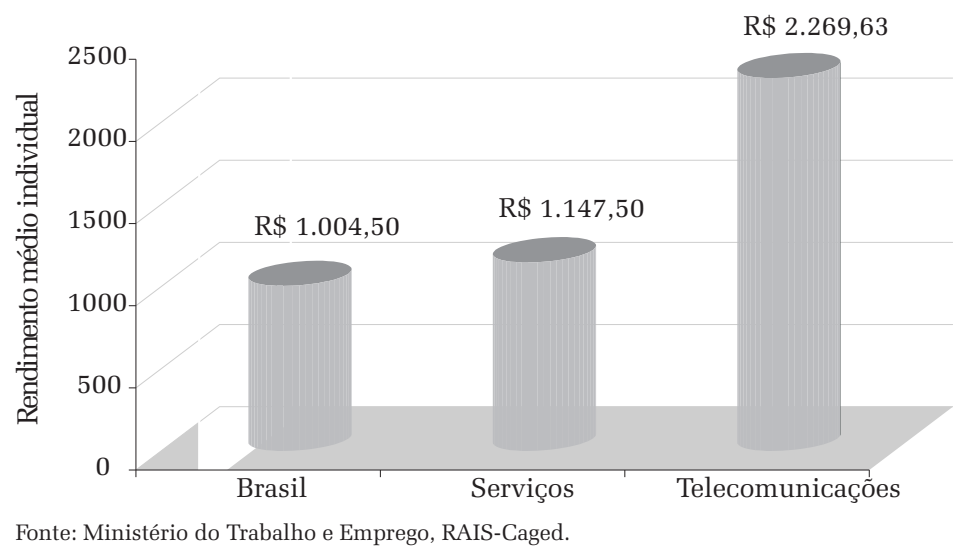

\footnotetext{
2 A Lei n $^{\circ}$ 10.888, de 24/06/2004, estabeleceu o salário mínimo de R\$260,00, vigente a partir da data de promulgação até $18 / 08 / 2005$, quando o salário mínimo foi reajustado.
} 
salário médio. No Brasil, o rendimento médio foi de R $\$ 1.004$, equivalente a 3,7 salários mínimos, indicando que aproximadamente $39 \%$ dos empregados no mercado de trabalho formal recebiam remuneração equivalente ou superior ao salário médio nacional. No setor de serviços, o rendimento médio foi de $\mathrm{R} \$ 1.147$, equivalente a 4,4 salários mínimos, indicando que $36 \%$ dos empregados recebiam remuneração superior ao salário médio nesse setor. A renda média do mercado de trabalho formal do Brasil (R\$1.004) é superada por $57 \%$ dos empregados nas atividades de telecomunicações. Enquanto $42 \%$ dos empregados de telecomunicações têm uma renda média igual ou superior a R $\$ 2.269$ (média do setor), no mercado de trabalho formal apenas $16 \%$ dos empregados receberiam esse nível de remuneração, e no setor de serviços 19\% dos empregados.

Outra mudança expressiva na caracterização dos empregos na atividade de telecomunicações diz respeito à redução do tempo em que os empregados mantêm seus vínculos de emprego com uma mesma empresa. Em 2004, cerca de 80\% dos empregados do setor de telecomunicações têm até cinco anos de emprego (60 meses), evidenciando uma inversão em relação ao período anterior à privatização (1994), quando 70\% dos empregados tinham mais de cinco anos de emprego. Esse fato expressa duas situações diferenciadas. Em primeiro lugar, as telecomunicações, hoje, constituem um setor com nova estrutura e novo perfil, em que o contingente de trabalhadores foi quase completamente renovado. A mudança marcante ocorreu no caso dos empregados com maior tempo de empresa. Em 1994, os empregados com mais de 10 anos de emprego representavam quase $60 \%$ dos trabalhadores, os quais sofreram redução após 1998, chegando em 2004 com representação de 9\%. Em segundo lugar, o mercado de trabalho das telecomunicações expressa uma situação de grande rotatividade. Em 2004, os empregados com até um ano de emprego eram $45 \%$, taxa que não sofre alterações significativas desde 2000, demonstrando que, nas telecomunicações, há grande rotatividade e mobilidade de emprego. Contudo deve-se consi- derar que houve grande geração de empregos entre 2003 e 2004. Em entrevistas realizadas em sindicatos de telecomunicações, nas empresas de telefonia fixa e móvel e com empregados no setor, existem evidências que os empregados estão em constante mobilidade de postos de trabalho, em busca de novas oportunidades intra-setor e extrasetor, isso porque a atual forma de organização das empresas dificultaria mobilidade ascendente de cargos e que as melhores oportunidades acabariam sendo buscadas no mercado de trabalho. Além disso, os empregados absorvidos pelo setor cada vez mais detêm maior escolaridade, muito em função das inovações tecnológicas, o que tem possibilitado a busca de novos empregos por parte significativa dos trabalhadores.

A situação do tempo de emprego na atividade de telecomunicações demonstra ser bastante diferenciada em relação ao mercado de trabalho formal e ao setor de serviços, principalmente no que se refere aos empregados com até um ano de emprego. No Brasil e no setor de serviços, os empregados em tal situação estão entre $22 \%$ e $30 \%$, respectivamente. Contudo, em 2004, o setor de telecomunicações não se caracteriza pela contratação a partir de vínculos temporários de emprego, ou através de contratos por tempo determinado, o que poderia justificar a grande participação de empregados com menos de um ano de casa. Pelo contrário, observou-se que 99\% dos vínculos de emprego são firmados por contratos baseados na Consolidação das Leis do Trabalho (CLT), por tempo indeterminado, segundo os dados da RAIS.

Na atividade de telecomunicações, observouse um aumento do número de empregos com maior jornada de trabalho, embora não fossem verificadas situações de jornada de trabalho muito curta ou excessiva. Em 2004, cerca de 50\% dos empregos são de jornada de trinta a quarenta horas semanais, e 45\% dos empregos são de jornada de quarenta a quarenta e quatro horas semanais. Empregos com jornadas de até vinte horas semanais nunca foram comuns na atividade de telecomunicações. Empregos com jornadas entre vinte e trinta horas semanais chegaram a 5\% entre 1994 e 
1998, mas reduziram sua participação posteriormente. As atividades de telecomunicações não se caracterizam por empregos de tempo parcial; pelo contrário, observou-se que, entre 2000 e 2004, aumentou a participação de empregos com jornadas de trinta a quarenta horas semanais e com mais de quarenta horas.

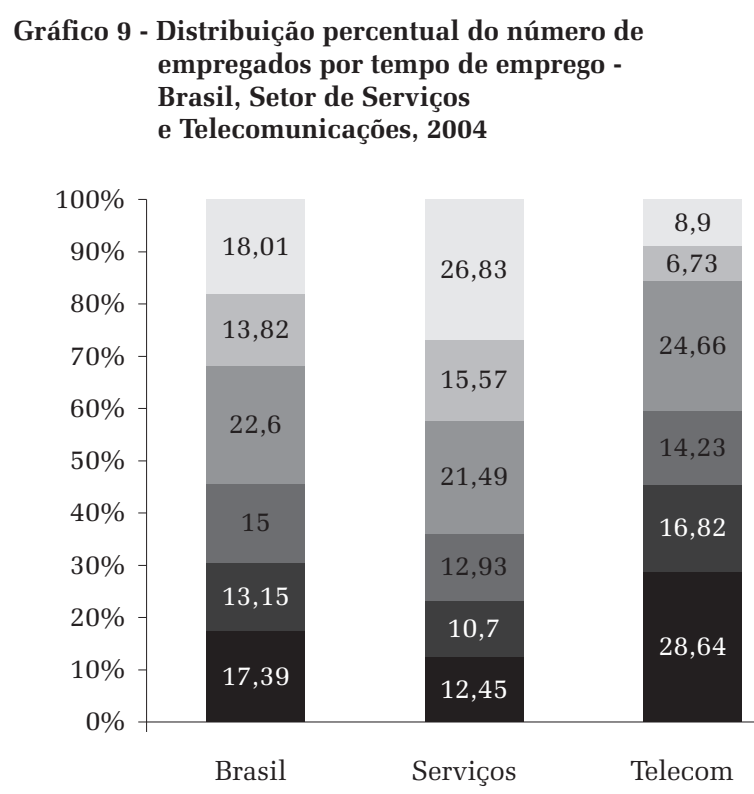

Até $5,9 \square 6,0$ a $11,9 \square 12,0$ a 23,9

24,0 a $59,9 \quad 60,0$ a $119,9 \quad 120$ ou mais

Fonte: Ministério do Trabalho e Emprego, RAIS-Caged. de construção civil. Nas atividades de telecomunicações (serviços), enquanto reduziu a participação masculina, aumentou a participação feminina. Em 1994, a participação de homens na atividade de telecomunicações era de quase $70 \%$, situação que sofreu modificação apenas nos últimos três anos, quando a participação de mulheres oscilou entre 40 e $42 \%$. A inserção das mulheres nesse mercado de trabalho ocorreu em razão da ampliação das atividades administrativas, de contato com o cliente e comercialização dos serviços, em detrimento das atividades operacionais e técnicas, ocupadas tradicionalmente por homens. A implementação do número de mulheres, contudo, não foi uma conseqüência imediata da privatização do setor. $\mathrm{O}$ aumento significativo da participação feminina no período, ocorreu entre o ano 2000 e 2002 e estabilizou-se em 2004. Esse é o período caracterizado pela expansão do segmento de telefonia móvel celular e pela liberalização do mercado das telecomunicações, que ocorreu em 2002.

$\mathrm{Na}$ atividade de telecomunicações, as muTheres compõem a maior parcela dos empregos com mais baixas remunerações, embora estejam com participação expressiva nos cargos de melhores salários. Em 2004, observou-se que 60\% das mulheres e 40\% dos homens ocupavam cargos com remuneração de até cinco salários mínimos, sen-
O perfil dos trabalhadores empregados na atividade de telecomunicações também sofreu profunda mudança entre 1994 e 2004.

A maior parte da mão-deobra do setor de telecomunicações tradicionalmente foi formada por homens. Entretanto, com as transformações no setor, parte significativa do contingente masculino foi transferida para as atividades de obras em telecomunicações, ${ }^{13}$ alocada no setor Fonte: Ministério do Trabalho e Emprego, RAIS-Caged.

${ }^{13}$ A participação de homens na atividade de obras em telecomunicações é de $90 \%$.
Gráfico 10 - Evolução da participação percentual dos empregados no setor de Telecomunicações, por sexo - Brasil 1994-2004

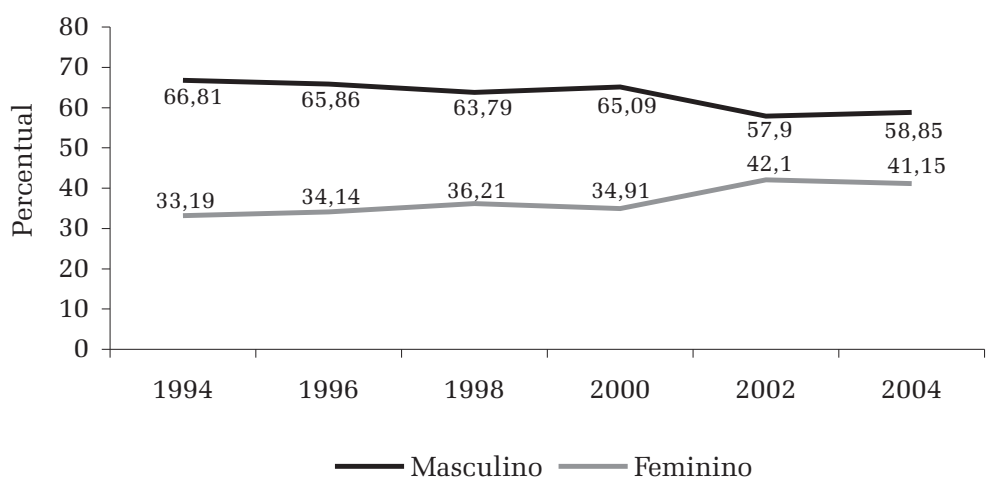


do que $29 \%$ das mulheres e $18 \%$ dos homens estão na faixa de rendimentos de até dois salários mínimos. Chama atenção, contudo, que, na faixa intermediária de rendimento (entre cinco e dez salários mínimos), a participação de homens e mulheres foi idêntica (18\%). A maior desigualdade, em termos de remuneração, ocorre nas faixas mais elevadas, em que $19 \%$ das mulheres e $38 \%$ dos homens estão nas faixas de rendimento superiores a dez salários mínimos. Convém destacar que a participação das mulheres nas atividades de telecomunicações cresceu nos últimos anos, e que, no caso dos homens, muitos são remanescentes das empresas estatais e do período em que as empresas estavam se ajustando, apresentando, por tais razões, em alguns casos, salários inflacionados em relação ao mercado das telecomunicações. A tendência recente, segundo os sindicatos, é que as empresas cada vez mais padronizem as remunerações, evitando que trabalhadores recebam remunerações diferenciadas para executar uma mesma função.

O incremento de trabalhadores mais jovens teve forte repercussão sobre a redução da idade média dos empregados no mercado de trabalho das telecomunicações, o que parece estar relacio- nado à comercialização dos novos produtos de tecnologia avançada e serviços de curto ciclo de vida, que entram e saem do mercado rapidamente. Em 1996, os empregados da atividade de telecomunicações com mais de quarenta anos de idade chegaram a representar $48 \%$ do contingente, participação que foi sendo reduzida gradualmente nos anos seguintes, quando chegou a $23 \%$ e $22 \%$, em 2002 e 2004, respectivamente, muito em razão das aposentadorias e demissões voluntárias entre 1996 e 1998. A participação de empregados entre trinta e trinta e nove anos sofreu a menor modificação, embora tenha também reduzido, passando de $36 \%$, em 1994, para 30\%, em 2004.

A redução de empregados dos estratos mais elevados de idade foi acompanhada pelo aumento dos empregados com menos de trinta anos de idade, os quais, em 1994, representavam $18 \%$ e passaram a representar quase $50 \%$ dos trabalhadores das atividades de telecomunicações, em 2004. Os empregados com até vinte e quatro anos passaram de 7\% em 1994 para 23\% em 2004, participação maior do que a dos empregados com mais de 40 anos. A redução da participação dos empregados com mais de quarenta anos, nas atividades de tele-

\section{Gráfico 11 - Evolução da participação percentual dos empregados no setor de telecomunicações} por faixa etária (em anos de idade) - Brasil 1994-2004

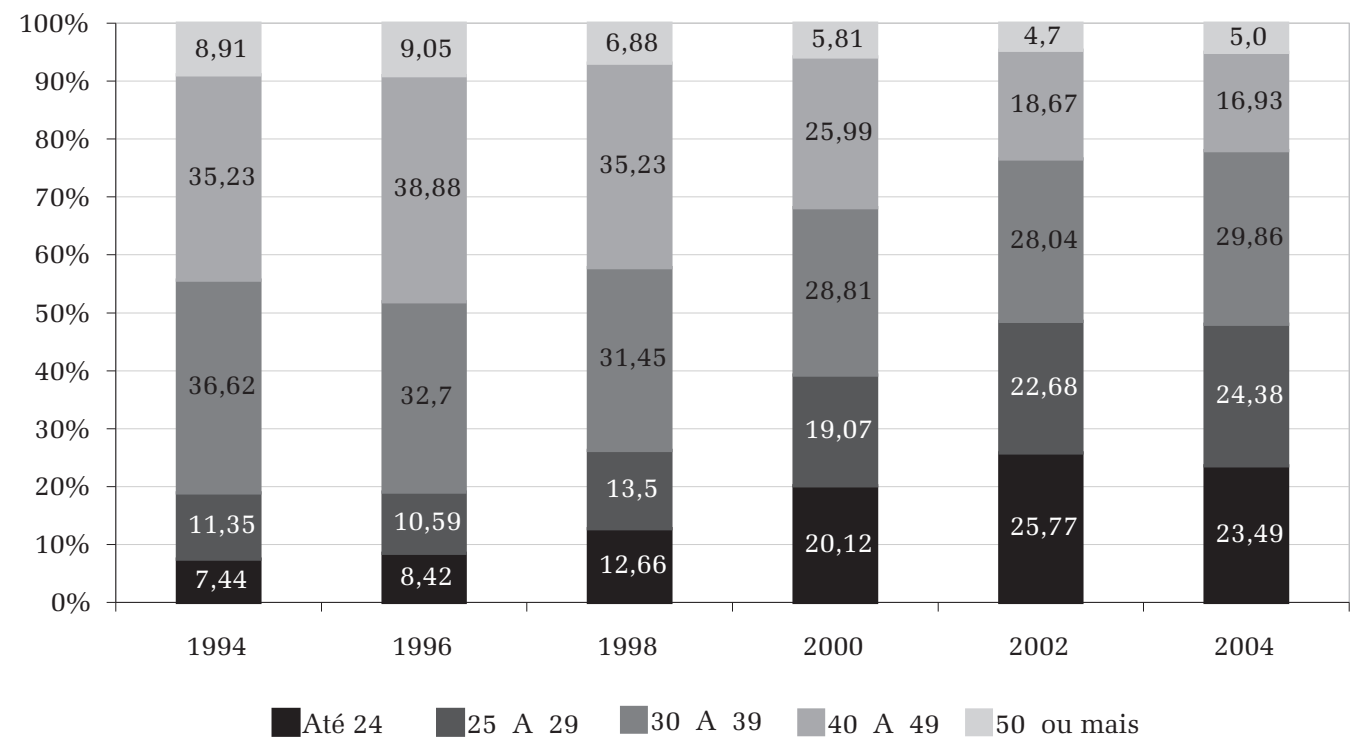

Fonte: Ministério do Trabalho e Emprego, RAIS-Caged. 
comunicações, implica que a idade média no setor, em 2004, seja de trinta e dois anos de idade, mais baixa que a do mercado de trabalho formal e que a do setor de serviços, em que a idade média dos empregados foi, respectivamente, trinta e cinco e trinta e sete anos.

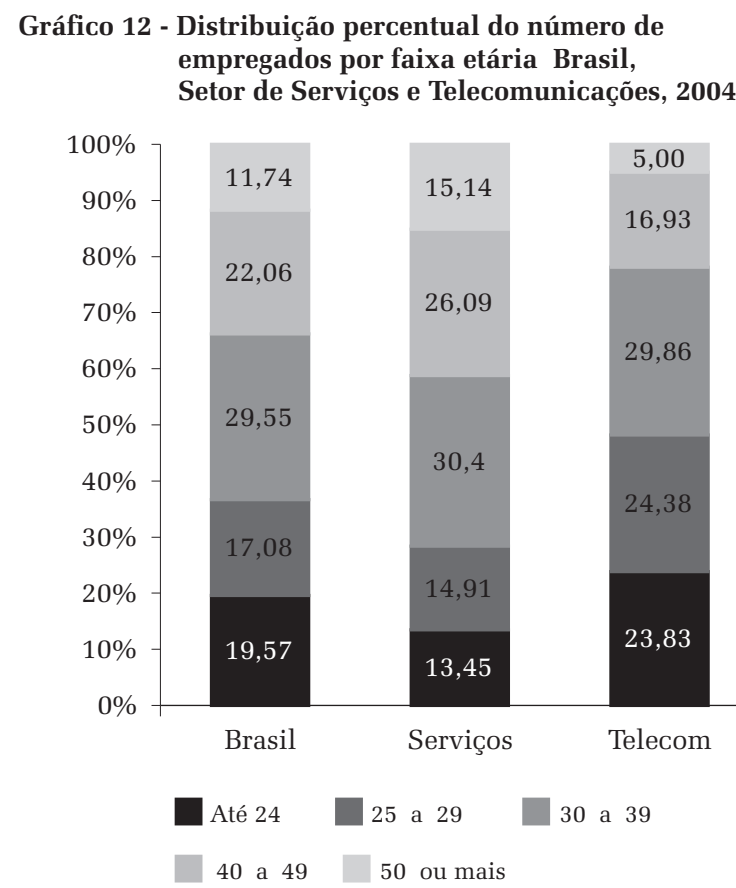

Fonte: Ministério do Trabalho e Emprego, RAIS-Caged.

As atividades de telecomunicações apresentam um mercado de trabalho que é mais aberto à inserção de trabalhadores mais jovens, quando comparado com o mercado de trabalho formal do Brasil e do setor de serviços. A atividade de telecomunicações também passou a se caracterizar por um contingente de trabalhadores com maior qualificação, considerando-se o crescimento expressivo em termos de escolaridade formal. Ou seja, houve, no período pós-privatização, a substituição de empregados com maior idade por trabalhadores mais jovens e com maior escolaridade. Em 2004, os empregados com ensino superior completo chegaram a 34\%, e quase 20\% estão cursando o ensino superior ou cursaram parte do ensino superior. Esse retrato demonstra a implementação dos maiores níveis de educação formal na atividade de telecomunicações em relação ao seu passa- do recente, embora, em 1994, já fosse alta a participação de empregados com escolarização superior (18,5\%). A participação dos empregados com escolarização média não sofreu mudança significativa no período analisado, mantendo-se em torno de 40\%. Em 1994, mais de 30\% dos empregados havia concluído, no máximo, o ensino fundamental, sendo que 7,6\% eram analfabetos. Em 2004, não havia mais empregados analfabetos, e o percentual de empregados com formação inferior ao ensino médio foi reduzido de $27 \%$ para $7 \%$.

A escolaridade dos empregados no setor é mais elevada que a do mercado de trabalho formal no conjunto e do setor de serviços. No Brasil, em 2004, a mão-de-obra empregada no mercado de trabalho formal apresentou baixa escolarização, sendo que $50 \%$ dos empregados possuíam apenas o ensino fundamental. O setor de serviços apresentou uma situação melhor, com uma participação de empregados com ensino superior de $23 \%$ contra 15\% do mercado de trabalho brasileiro; mesmo assim, predominava o ensino fundamental (40\%). No setor de telecomunicações, o percentual de homens e mulheres com escolaridade superior é equivalente, $35,6 \%$ e $31,5 \%$, respectivamente. No caso

Gráfico 13 - Evolução da participação percentual dos Empregados no setor de telecomunicações por escolaridade Brasil 1994-2004

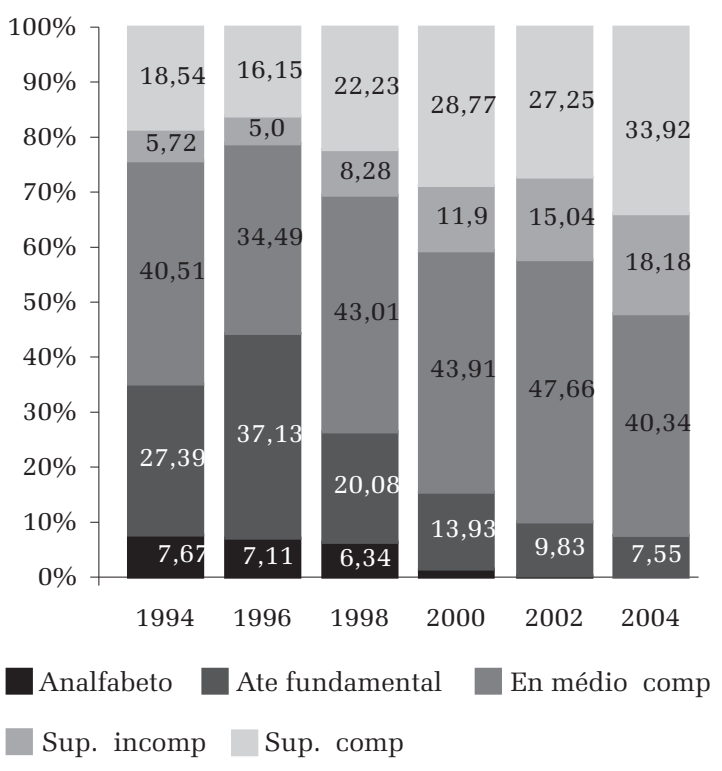

Fonte: Ministério do Trabalho e Emprego, RAIS-Caged. 
Gráfico 14 - Distribuição percentual do número de Empregados por faixa de escolarização Brasil, Setor de Servicos e

Telecomunicações, 2004

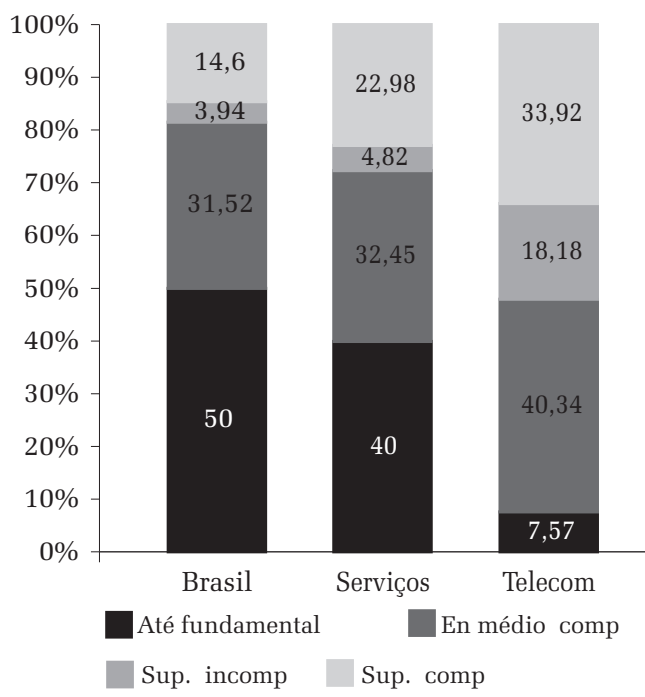

Fonte: Ministério do Trabalho e Emprego, RAIS-Caged.

Nota: Número de vínculos de emprego formais ativos no dia 31

de dezembro do referido ano, declarado pelos respectivos

Estabelecimentos.

* Escolaridade em 31 de dezembro. do mercado de trabalho formal do Brasil e do setor de serviços, o percentual de mulheres com escolaridade superior é o dobro do dos homens: 10,4 são homens e 20,9 são mulheres no Brasil; 17,7 são homens e 28,4 são mulheres no setor de serviços (RAIS). Existem indícios que apontam para uma melhor condição de emprego das mulheres nas atividades de telecomunicações, quando comparada ao contexto mais amplo. Observou-se também que a idade dos empregados tem repercussão sobre a remuneração média. Nas atividades de telecomunicações, os empregados, independentemente da idade, têm remuneração média mais elevada que os empregados do setor de serviços e do mercado de trabalho formal.

Assim como a idade, a escolarização também apresenta repercussão sobre a remuneração média dos empregados. No Brasil, no setor de serviços e na atividade de telecomunicações, observou-se que quanto maior o grau de escolaridade, maior a remuneração média individual do empregado. Contudo chama a atenção que, nas teleco-

Tabela 1 - Distribuição do número de vínculos de emprego, massa salarial e rendimento médio individual por faixa etária* - Brasil, Setor de Serviços e Telecomunicaçóes, 2004

\begin{tabular}{|c|c|c|c|c|c|c|}
\hline Nível de agregação & Faixa Etária & $\mathrm{N}^{\circ}$ de empregos & $\% \mathrm{Col}$ & Massa salarial $(\mathbf{R} \$)^{* *}$ & $\% \mathrm{Col}$ & $\begin{array}{c}\text { Renda média } \\
\text { (R\$) }\end{array}$ \\
\hline \multirow{7}{*}{$\begin{array}{l}\text { Atividade de } \\
\text { Telecomunicações }\end{array}$} & Até 24 anos & 27.003 & 23,83 & $20.523 .893,97$ & 7,98 & 760,05 \\
\hline & 25 a 29 & 27.622 & 24,38 & $46.195 .731,02$ & 17,96 & $1.672,42$ \\
\hline & 30 a 39 & 33.832 & 29,86 & $97.559 .022,62$ & 37,94 & $2.883,63$ \\
\hline & 40 а 49 & 19.180 & 16,93 & $68.273 .165,65$ & 26,55 & $3.559,60$ \\
\hline & 50 a 64 & 5.603 & 4,95 & $24.486 .933,45$ & 9,52 & $4.370,32$ \\
\hline & 65 ou mais & 58 & 0,05 & $128.829,72$ & 0,05 & $2.221,20$ \\
\hline & Total & 113.298 & 100,00 & $257.167 .576,43$ & 100,00 & $2.269,83$ \\
\hline \multirow{7}{*}{ Setor de Serviços } & Até 24 anos & 2.287 .006 & 13,45 & $1.294 .894 .965,06$ & 6,64 & 566,19 \\
\hline & 25 a 29 & 2.535 .024 & 14,91 & $2.163 .397 .286,27$ & 11,09 & 853,40 \\
\hline & 30 a 39 & 5.168 .241 & 30,40 & $5.892 .048 .112,83$ & 30,20 & $1.140,04$ \\
\hline & 40 a 49 & 4.435 .751 & 26,09 & $6.367 .403 .648,05$ & 32,64 & $1.435,47$ \\
\hline & 50 a 64 & 2.404 .300 & 14,14 & $3.547 .206 .259,43$ & 18,18 & $1.475,35$ \\
\hline & 65 ou mais & 170.161 & 1,00 & $243.313 .713,81$ & 1,25 & $1.429,90$ \\
\hline & Total & 17.001 .020 & 100,00 & $19.508 .771 .471,17$ & 100,00 & $1.147,50$ \\
\hline \multirow{7}{*}{$\begin{array}{l}\text { Brasil (Mercado } \\
\text { formal) }\end{array}$} & Até 24 anos & 6.146 .382 & 19,57 & $3.233 .247 .315,47$ & 10,25 & 526,04 \\
\hline & 25 a 29 & 5.366 .203 & 17,09 & $4.145 .214 .647,82$ & 13,14 & 772,46 \\
\hline & 30 а 39 & 9.280 .447 & 29,55 & $9.641 .920 .286,38$ & 30,56 & $1.038,94$ \\
\hline & 40 a 49 & 6.928 .187 & 22,06 & $9.374 .162 .875,72$ & 29,71 & $1.353,04$ \\
\hline & 50 a 64 & 3.460 .560 & 11,02 & $4.854 .468 .904,38$ & 15,39 & $1.402,79$ \\
\hline & 65 ou mais & 225.142 & 0,72 & $299.566 .820,06$ & 0,95 & $1.330,56$ \\
\hline & Total & 31.407 .576 & 100,00 & $31.549 .164 .378,85$ & 100,00 & $1.004,50$ \\
\hline
\end{tabular}

Fonte: Ministério do Trabalho e Emprego, RAIS-Caged.

Nota: Número de vínculos de emprego formais ativos no dia 31 de dezembro do referido ano, declarado pelos respectivos estabelecimentos.

* Faixa etária em 31 de dezembro.

** Massa salarial em dezembro de 2004. 
municações, a remuneração média dos empregados com educação superior apresenta substancial diferença em relação aos empregados de escolaridade mais baixa na própria atividade de telecomunicações e em relação aos empregados com ensino superior no Brasil e no setor de serviços. Nesse sentido, nas telecomunicações, quanto maior a escolaridade dos empregados, maior a remuneração e melhores as perspectivas de condições de emprego em termos salariais. Isso contribui com a idéia de que, em atividades tecnológicas, a educação superior incrementa a remuneração mais do que no conjunto das atividades. Nas telecomunicações, os empregados com nível superior detêm $66 \%$ da massa salarial, enquanto que, no Brasil, estes detêm 36\% da massa salarial, e no setor de serviços, 47\% (Tabela 2).

A renovação do contingente de empregados na atividade de telecomunicações tem caminhado lado a lado com a evolução do setor, e alguns dos aspectos referentes às características dos empregos e ao perfil dos trabalhadores podem ser analisados paralelamente ao crescimento do número de acessos telefônicos no setor.

A expansão das telecomunicações apresen- ta relação inversa com a experiência dos trabalhadores nas empresas, essa considerada através do tempo de emprego, indicando, hipoteticamente, que a expansão esteja mais inclinada ao novo perfil dos empregados, maior escolarização, menor média de idade. No Brasil, a expansão mais significativa dos acessos telefônicos ocorreu no ano 2000, quando a participação dos empregados com mais de dez anos de empresa foi reduzida para menos de 20\%. A expansão do setor também acompanha o incremento da participação de empregados mais jovens, que se supõe sejam mais escolarizados e com maior contato com novas tecnologias. Os empregados mais jovens parecem também mais motivados a ampliar sua escolaridade, aspecto que os levaria a almejarem formação permanente; por exemplo, quando concluem o curso superior, podem se ver frente a uma nova perspectiva no setor e perante novas oportunidades de emprego ou carreira no setor. Tal aspecto poderia justificar, em parte, a alta rotatividade ${ }^{14}$ no setor de telecomunicações, mas convém destacar que a rotatividade não impede a expansão do setor; pelo contrário, a maior expansão das empresas ocorre quando a participação de empregados

Tabela 2 - Distribuição do número de vínculos de emprego, massa salarial e rendimento médio individual por grau d instrução* - Brasil, Setor de Serviços e Telecomunicaçóes, 2004

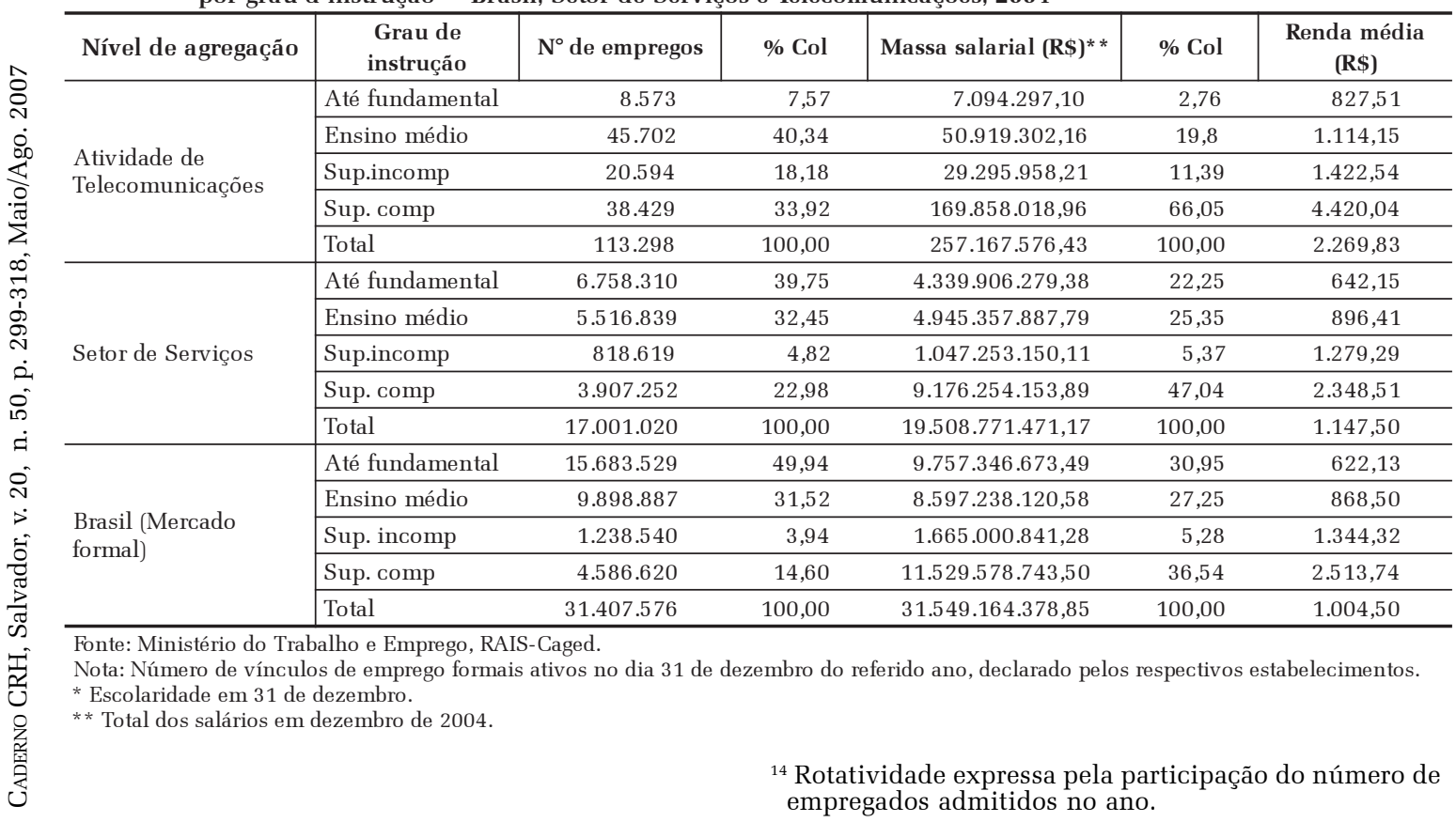


admitidos no ano chega a índices superiores a 35\% (o que ocorre desde 2000). O crescimento na participação de empregados com escolaridade maior que o ensino médio (ensino superior e ensino superior incompleto) também acompanha a evolução do setor, embora em 1998, o índice de empregados com escolaridade mais elevada já fosse alto (30\%); porém, a produtividade era baixa. Essa situação leva a considerar que o aumento da escolaridade seja melhor para os empregados do que para as empresas.

A renovação do contingente de trabalhadores do mercado de trabalho das telecomunicações estaria ocorrendo através da contratação de empregados mais jovens e mais escolarizados, e não por empregados mais experientes. Segundo sindicatos e empresas, os novos empregados do setor, com menos tempo de emprego, mais jovens e mais escolarizados, estariam mais propensos a formarse em uma nova cultura empresarial e sindical. Alguns estudos indicam que a maior escolaridade poderia afastar o empregado do sindicalismo, mas essa questão parece estar relacionada também a outros fatores, por exemplo, a juventude dos empregados. Como apontado por lideranças sindicais em entrevistas, os empregados mais jovens não conhecem a "cultura tradicional" do setor e "não reconhecem suas lutas". Afirmam que a exigência do aumento de salário para trabalhadores que estão mais preocupados em garantir o emprego e receber um salário, seja ele qual for - é injustificável para os empregados mais jovens, preocupados em distanciarem-se do ambiente de incerteza quanto ao futuro.

A experiência do empregado (tempo de emprego), ao que tudo indica, perdeu seu valor nas empresas de telecomunicações, em que as mudanças ocorrem em ritmo acelerado. O empregado mais experiente torna-se defasado e, de certa maneira, empecilho às mudanças freqüentes. Mas isso não significa que os empregados que estão se formando no setor, recentemente, não estejam se adaptando à lógica da inovação e competitividade. O que tem sido mais importante, no contexto das atividades de telecomunicações, parece ser a moti- vação, baseada no "conhecimento" e na "disposição”. Destaca-se, ainda, que o crescimento do número de trabalhadores com menos de dez anos de emprego foi acompanhado pela redução do número de empregados com salários mais elevados. Esse fato pode supor que a redução da participação de empregados com salários mais elevados também esteja relacionada às carreiras que ainda são curtas, diferentemente do que se observou no período anterior a 1998. Além disso, o crescimento da participação de empregados com até vinte e nove anos acompanha o crescimento dos empregados com até doze meses no emprego, indicando que os empregados mais jovens estão em constante mobilidade, o que tende a ampliar a rotatividade, mas que não necessariamente venha a representar, até o momento, uma condição desfavorável de emprego. Alguns depoimentos de trabalhadores sugerem que ainda há um processo de ajuste ao novo perfil do setor, possibilitando que os empregados procurem melhores posições de emprego.

\section{CONSIDERAÇÕES FINAIS}

O quadro atual do emprego nas atividades de telecomunicações e a situação das condições de emprego não podem ser analisados em separado das profundas mudanças que ocorreram entre 1994 e 2004 nesse setor e que redesenharam a sua estrutura organizacional e produtiva no Brasil. As transformações na natureza das atividades e no perfil do setor sugerem uma nova configuração das telecomunicações em termos de trabalho, com uma quase completa renovação dos trabalhadores empregados. Tais aspectos estão, de certa maneira, interligados, e sua convergência torna limitadas as observações sobre pontos isolados das mudanças para justificar uma abordagem pessimista sobre a qualidade do emprego no setor, como, por exemplo, enfatizar a redução do percentual de empregados nas faixas de rendimento mais elevadas. Observou-se que as condições de emprego e o perfil dos empregados nas telecomunicações apresentam maior qualidade e significativa diferenciação 
em relação ao seu contexto mais amplo, formado pelo mercado de trabalho do Brasil no conjunto e o mercado de trabalho do setor de serviços. Ou seja, poder-se-ia entender que os empregos nas telecomunicações teriam sofrido uma redução na qualidade, quando comparados com seu passado na condição pública. Contudo, a nova configuração do setor impede que se tome essa comparação como elemento decisivo na interpretação da qualidade do emprego no caso analisado, uma vez que não houve deterioração do emprego para os trabalhadores do setor, e sim uma mudança no quadro de empregos para os novos trabalhadores que foram empregados. O ponto decisivo na interpretação da qualidade do emprego, nesse caso, consiste em considerar as observações sobre o setor, ponderadas com o contraste com o mercado de trabalho mais amplo. O certo é que a configuração atual das atividades de telecomunicações e as conseqüentes mudanças contribuíram na sua diferenciação em relação ao contexto mais amplo.

O que queremos destacar é que há um diferente padrão de comportamento dos indicadores de qualidade do emprego, a depender das atividades econômicas analisadas e dos processos pelos quais elas passam. A redução do número de empregos, logo após a expansão inicial do setor, foi revertida quando o mesmo começou a diversificar produtos e serviços, efetivando o novo perfil produtivo assumido pelo setor. A perspectiva anterior e logo posterior à privatização, de perdas no número de empregos e precarização das relações de trabalho, confirmou-se inicialmente, mas depois foi superada pela nova conjuntura e dinâmica que se desenvolveu internamente ao setor de telecomunicações, com indícios de expansão no número de empregos e melhora na qualidade do emprego, após 2003. A retomada de crescimento do número de empregos pode estar relacionada à reinserção de empregados terceirizados no período anterior e também à inclusão de trabalhadores antes contratados como pessoa jurídica, como vem sido apontado pelos sindicatos e empresas de telecomunicações. Uma melhoria na qualidade do emprego, por sua vez, pode estar, portanto, relaciona- da ao ajuste das organizações e dos trabalhadores atuantes no setor ao novo perfil por ele requerido.

As condições de emprego na atividade de telecomunicações parecem ter sofrido alguma deterioração quando a recente situação é comparada com a situação vigente no período de controle público. Porém, mais recentemente e no âmbito setorial, a situação do emprego nas telecomunicações tem posição destacada quando o parâmetro de análise é o contexto maior. O quadro de empregos na atividade de telecomunicações, entre 1994 e 2004, caracterizou-se pela redução do tempo de emprego, independentemente da significativa melhoria no grau de instrução dos empregados. É importante lembrar, ainda, que o setor não se caracteriza pela contratação apenas de vínculos temporários de emprego e que, portanto, a rotatividade elevada não poderia ser explicada apenas pela instabilidade. Como foi destacado, existem indícios de que as organizações e os trabalhadores atuantes no setor vêm se adequando à nova realidade econômica. O estudo apresentou importantes evidências que apontam para algumas tendências, mas que ainda precisam ser melhor investigadas.

O perfil dos empregados, diferentemente das condições de emprego, foi implementado na instrução dos empregados, na inserção de trabalho feminino e na incorporação de trabalhadores mais jovens. O incremento do grau de instrução dos empregados ocorre tanto quando a comparação é com o passado do setor (empresas públicas), como quando o parâmetro de análise é o contexto maior. Curiosamente, a atividade de telecomunicações passou a atrair trabalhadores mais jovens, mais qualificados em termos de escolaridade que os antigos trabalhadores do setor, e dispostos a receber remuneração mais baixa, embora sua remuneração, hoje, seja significativamente superior à do mercado de trabalho brasileiro e à do setor de serviços. A perspectiva dos empregados estarem dispostos a receber menores salários poderia ser questionada, tomando-se por referência o aumento do desemprego. Entretanto, entrevistas revelam a preocupação das empresas de telecomunicações com certa escassez de empregados qualificados ou de- 
mandados pelas empresas, o que tem provocado uma mobilidade freqüente de empregados intrasetor. Em muitos casos, as empresas precisam buscar trabalhadores nas próprias empresas concorrentes, para cargos iguais, mas com atrativos no salário ou benefícios.

A análise longitudinal permitiria dizer que houve deterioração das condições de emprego na atividade de telecomunicações, principalmente em termos de remuneração e tempo de emprego, embora não se possa negar que outros fatores relacionados à qualidade do emprego foram ampliados como a escolarização dos trabalhadores e a produtividade. Além disso, a análise comparativa revelou diferenciação significativa, em termos positivos, entre as telecomunicações e o seu contexto mais amplo. Contudo parece ser prematuro esboçar uma avaliação positiva ou negativa das mudanças na situação do emprego nas atividades de telecomunicações. A perspectiva em pauta é tentar evitar cair da discussão de "bons" e "maus" empregos, atacando sob diversas formas essa problemática. O foco que merece maior destaque parece ser o de analisar como as mudanças setoriais radicais têm repercutido sobre a situação do emprego no setor, especialmente considerando-se as condições de emprego e o perfil dos empregados, aspectos que concernem à qualidade do emprego. O recente quadro das características dos empregos, das condições de emprego e do perfil do contingente de empregados na atividade de telecomunicações sugere que a qualidade do emprego, na atividade de telecomunicações, seria privilegiada em relação ao seu contexto mais amplo. No final do período analisado e em termos comparativos, poder-se-ia dizer que a qualidade do emprego, nas telecomunicações, merece boa avaliação: os salários são mais elevados que no mercado de trabalho formal no Brasil e no setor de serviços; a escolaridade dos trabalhadores que estão empregados é mais elevada; os contratos de trabalho são por tempo indeterminado, as jornadas são completas. Uma série de atributos estaria incorporada para fundamentar a constituição de "bons empregos" no setor de telecomunicações. Os dados apresentado indicam uma vinculação importante entre a reestruturação do setor, tanto tecnológica quanto organizacionalmente, as condições de emprego e o perfil dos empregados. Contudo fica latente a questão da grande rotatividade, o que poderia indicar uma nova tendência no mercado de trabalho das atividades econômicas de maior padrão tecnológico, o que merece maior investigação.

(Recebido para publicação em junho de 2007) (Aceito em agosto de 2007)

\section{REFERÊNCIAS}

ANATEL. Agência Nacional de Telecomunicações. < http:/ /www.anatel.gov.br> (Indicadores da base on line).

ABRANTES, Carvalho. A qualidade do emprego no contexto europeu. Revista Formar, Lisboa: Instituto do Emprego e Formação Profissional, n.50, p.17-23, mar., 2005.

BALBONTÍN, Patricio Rozas. Privatización, reestruturación industrial y prácticas regulatórias en el sector telecomunicaciones. Santiago do Chile: División de Recursos Naturales e Infraestructura/CEPAL/Nações Unidas, 2005. (Série recursos naturales e infraestructura)

BARROS, Ricardo Paes de; MENDONÇA, Rosane Silva Pinto de. Uma avaliação da qualidade do emprego no Brasil. Texto de Discussão, Rio de Janeiro, IPEA n. 381, 75p, 1995.

BÜCHNER, Lutz Michael; RÜCKERT, Klaus. The Telecommunicatinos service sector in Germany: industrial relations in Deutsche Telekon: from monopoly to competition. In: INTERNATIONAL CONGRESS, 25, Oct., 2004. Las Vegas; Nevada: LASA, 2004. 26 p. Digitado.

CAMPOS, Mabel Jaqueline Carmona de; MOUTINHO, Lúcia Maria Góes; CAMPOS, Luís Henrique Romani de. Reestruturação produtiva e qualidade do emprego formal na indústria têxtil: um estudo comparativo entre as regiões nordeste e sul. [S.l.,s.n.,s.d.]. 18p. Arquivo Digital.

CELLA, Gilciane. Implantação de sistemas integrados de gestão: um estudo exploratório na empresa de telefonia celular Telet S. A. 2002. Dissertação (Mestrado Profissionalizante) - UFRGS, Escola de Administração, Programa de Pós-Graduação em Administração. Porto Alegre.

CURTINAZ DA SILVA, Paulo Herbert. Trajetórias ocupacionais de trabalhadores desligados do setor de telecomunicações. 2003. Dissertação (Mestrado) - UFRGS/ IFCH, Programa de Pós-Graduação. Porto Alegre.

DORES, Adely Maria Branquinho das. Telecomunicações o novo cenário. Revista do Banco Nacional de Desenvolvimento Econômico e Sustentável. BNDES. Rio de Janeiro, v. 11. Jun., 1999. Disponível em: <http:// www.bndes.gov.br/conhecimento/revista/rev1110.pdf> Acesso em: 14 fev., 2006.

GALINA, Simone Vasconcelos Ribeiro. Desenvolvimento global de produtos: o papel das subsidiárias brasileiras de fornecedores de equipamentos de telecomunicações. 2003. (Tese) Doutorado. São Paulo: Escola Politécnica Engenharia - Universidade de São Paulo. 
GORDINHO, Margarida Cintra. Telecomunicações: memória. São Paulo: Marca d'Água, 1997

GUIMARÃES, Sônia Maria Karam. As telecomunicaçõe no Brasil após a privatização. In: PICCININI, Valmíria Carolina; HOLZMANN, Lorena; KOVÁCS, Ilona (Orgs.) O mosaico do trabalho na sociedade contemporânea: persistências e inovações. Porto Alegre: Ed. UFRGS, 2006. p. 145-175

INFANTE, Ricardo (Ed.). La calidad del empleo: la experiencia de los países latiniamericanos y de los Estados Unidos. Santiago-Chile: OIT, 1999. 264p.

KATZ, Harry. (Ed.). Telecommunications. Restructuring work and employment relations worldwide. Ithaca: ILR Press; Cornell University, 1997.

LARANGEIRA, Sônia Maria Guimarães. Privatization and deregulation of telecommunications in Brazil: the global influence and local implications. In: BEUKEMA, Leni; CARILLO, Jorge Hector. (Orgs.). Globalism/Localism at work. Amsterdã (NL), 2004. p. 75-98.

A reestruturação das telecomunicações e os sindicatos Revista Brasileira de Ciências Sociais. São Paulo, v. 18, n. 52, p. 81-106, jun., 2003.

. Reestruturação no setor das telecomunicações: inovações tecnológicas, privatizaçóes e desregulamentação: aspectos da experiência internacional. Revista Latinoamericana de Estúdios del Trabajo, [S.l.], v. 4, n. 8, p. 159-178, 1998.

MELO, Paulo Roberto de Souza; GUTIERREZ, Regina Maria Vinhais. Telecomunicações pós-privatização: perspectivas industriais e tecnológicas. Rio de Janeiro: BNDES, n.8, 1998. Disponível em: http://www.bndes.gov.br > Acesso em: 23 jun., 2005.

MOCELIN, Daniel Gustavo; CORRÊA, Luís Fernando Santos. Novos perfis ocupacionais: empregados de call centers no setor de telecomunicações. 2003. 38p. Relatório de Pesquisa. http://www.ufrgs.br/ppgsocio/producao . Porto Alegre: Departamento de sociologia, UFRGS.

MOCELIN, Daniel Gustavo. Qualidade do emprego em contexto de mudança tecnológica: o caso das operadoras de telefonia móvel celular. 2006. 211p. Dissertação (Mestrado) - UFRGS, Programa de Pós-Graduação em Sociologia. Porto Alegre.

Aspectos da terceirização nas telecomunicações: complexificação de uma empresa terceirizada no Rio Grande do Sul. In: CONGRESSO DA ALAS, 25, ago., 2005 Porto Alegre, UFRGS. 22p. Disponível em: http:// www.ufrgs.br/ppgsocio/producao> Acesso em: 16 fev., 2006.

MOREIRA CARDOSO, Adalberto. Trabalhar, verbo tran sitivo. Destinos profissionais dos deserdados da indústria automobilística. Rio de Janeiro: Ed. FGV, 2000. 252p.

MTE. Ministério do Trabalho e Emprego. Programa de Disseminação do Ministério do Trabalho e Emprego (PDET) (Bases estatísticas RAIS-Caged). Disponível em: <http://www.mte.gov.br http://www.mte.gov.br/Menu/ Estatisticas $/>$.
NEVES, Maurício dos Santos. O setor de telecomunicações. In: RIBEIRO, Alexandre Dórea (Ed.). BNDES 50 anos - Histórias Setoriais. Rio de Janeiro: BNDES, 2002. Disponível em: http://www.bndes.gov.br/conhecimento/ livro setorial/setorial13.pdf $><$ e $<$ http:// www.bndes.gov.br/conhecimento/publicacoes/catalogo/ livsetorial.asp> Acesso em: 20 fev., 2006.

NOVAES, Ana. Privatizacão do setor de telecomunicacões no Brasil. In: PINHEIRO, Armando Castelar; FUHASAKU, Kiichiro (Eds). A privatização no Brasil: o caso dos serviços de utilidade pública. Brasília: BNDES/ OCDE, 2000. Cap. 5, p. 146-177.

OIT. Organización Internacional del Trabajo. Calidad de los nuevos empleos en los noventa. Informa OIT Panorama Laboral '97. Oficina Regional para América Latina e el Caribe. Disponible em: <http://www.oit.org.pe/spanish/ 260ameri/publ/panorama/1997/calidad.html> Acesso em: 6 abr., 2006.

PIRES, José Cláudio Linhares. A reestruturação do setor de telecomunicações no Brasil. Revista do BNDES, Rio de Janeiro, v. 11., jun., 1999.

RUDUIT GARCIA, Sandro. Privatização e emprego no setor de telecomunicações: novas oportunidades ou degradacão do trabalho? O caso do Rio grande do Sul, Brasil. Scripta Nova - Revista Electrónica de Geografia e Ciencias Sociales. Barcelona: Universidade de Barcelona, v.8, n. 170, ago., 2004

SILVA, Clarissa S. P da. Competição estratégica no setor de telefonia móvel celular no estado do Rio Grande do Sul no período de 1999 a 2001. 2004. Dissertação (Mestrado) - UFRGS, PPG Economia. Porto Alegre.

TELECO. Site especializado em telecomunicações. Diversos estudos, tutoriais, compilação de dados e comentários sobre o setor de telecomunicacões e sobre empresas de telecomunicação. Disponível em: < http:// www.teleco.com.br>

TOKMAN, Víctor E. Prólogo. In: INFANTE, Ricardo (Ed.). La calidad del empleo: la experiencia de los países latiniamericanos y de los Estados Unidos. Santiago-Chile: OIT, 1999. 264p.

WALTER, Jorge. Privatizaciones y relaciones laborales em la telefonia latinoamericana. Revista Latinoamericana de Estúdios del Trabajo, [S.l.], v. 4, n. 8, . p. 89-107, 1998

WOHLERS, Márcio. A reforma do modelo de telecomunicações: o menu internacional e a opção brasileira. In: TAPIA, Jorge Ruben Biton; RALLET, Alain (Orgs). Telecomunicações, desregulamentação e convergência tecnológica: uma análise comparada. Campinas, SP: UNICAMP, 1999. p. 43-73. (Coleção pesquisas, 2) 


\section{QUALIDADE DO EMPREGO NAS TELECO-} MUNICAÇÕES PÓS-PRIVATIZAÇÃO

\section{Daniel Gustavo Mocelin}

$\mathrm{O}$ artigo propõe uma reflexão sobre a qualidade do emprego nas atividades de telecomunicaçôes, que, no Brasil, passaram por recente processo de privatização, caracterizando um novo cenário empresarial, marcado por inovações tecnológicas, expansão comercial e competição de mercado. Frente ao novo perfil assumido pelo setor de telecomunicações, pergunta-se qual a situação da qualidade do emprego nas telea privatizacão. No ensaio, foi realizada uma abordagem longitudinal sobre a evolução das condições de emprego nas telecomunicações, no período entre 1994 e 2004, e uma análise comparativa entre as condições de emprego nas telecomunicações e no contexto mais amplo em que estão inseridas, a fim de estabelecer algumas reflexões sobre a qualidade do emprego para o cenário empresarial constituído após a privatização. Para isso, são analisados alguns aspectos concernentes à qualidade do emprego tais como o comportamento de dimensões como remuneração, tempo de emprego, jornada de trabalho, tipo de contrato de trabalho, escolarização dos empregados e inserção das mulheres, bem como alguns contrastes entre as atividades de telecomunicações e seu contexto mais amplo, o mercado de trabatrabalho do Brasil em seu conjunto. A análise da situação do emprego na atividade de telecomunicacões baseia-se nos dados disponíveis na Relação Anual de Informaçỗes Sociais (RAIS) do Minis tério do Trabalho e Emprego do Brasi (MTE). comunicações, quase uma década após lho do setor de serviços e o mercado de

\section{QUALITY OF EMPLOYMENT IN THE TELECOMMUNICATIONS POST- PRIVATIZATION}

Daniel Gustavo Mocelin

This paper proposes a reflection about the quality of employment in the activities of telecommunications that recently underwent a privatization process in Brazil, characterizing a new usiness scenery, marked by technological innovations, commercial expansion and market competition. Regarding the new profile taken by the telecommunications sector, it is wondered what is the situation in the quality of employment in telecommunications almost one decade after the privatization. This paper used a longitudinal approach about the evolution of employment conditions in telecommunications in the period between 1994 and 2004 and a comparative analysis among the employment conditions in telecommunications and in the wider context in which it is inserted, in order to establish some reflections about the quality of the employment for the business scenery that appeared after the privatization. For that, some aspects are analyzed concerning the quality of employment, such as the behavior of dimensions like remuneration, time of employment, duration of the work day, kind of employment contract, the employees education and women's insertion, and some contrasts among the activities of telecommunications and its wider context, the labor market of the services sector and the labor market in Brazil as a whole. The analysis of the situation of employment in the activity of telecommunications is based on the data available in the Annual Report of Social Information (in portuguese, RAIS) of Ministry of Labor and Employment of Brazil (in portuguese, MTE).

PALAVRAS-CHAVE: emprego, qualidade do emprego, reestruturação do setor de telecomunicações, privatização do setor de telecomunicações, inovações tecnológicas.
Keywords: employment, quality of employment, restructuring of the telecommunications sector, privatization of the telecommunications sector technological innovations.

\section{LA QUALITÉ DE L'EMPLOI DANS LES TELECOMMUNICATIONS APRES LEUR PRIVATISATION}

\section{Daniel Gustavo Mocelin}

L'article propose une réflexion sur la qualité de l'emploi dans les activités de télécommunications qui sont passées récemment, au Brésil, par un processus de privatisation. Ceci permet de caractériser un nouveau scénario pour les entreprises, marqué par les innovations technologiques, l'expansion commerciale et la compétition du marché. Face à ce nouveau profil assumé par le secteur des télécommunications, on se demande quelle est la situation de la qualité de l'emploi dans les télécommunications après quasi une décennie de privatisation. On a procédé à une approche longitudinale sur l'évolution des conditions de l'emploi au sein des télécommunications sur une période allant de 1994 à 2004. On a également fait une analyse comparative entre les conditions d'emploi dans les télécommunications, et dans le contexte plus ample dans lequel elles sont insérées, afin d'en arriver à quelques réflexions sur la qualité de l'emploi pour un scénario d'entreprise constitué après la privatisation. Pour cela, certains aspects concernant la qualité de l'emploi ont été analysés tels que le comportement de facteurs comme la rémunération, le temps de service, la journée de travail, le type de contrat de travail, la scolarisation des employés et l'insertion des femmes et quelques contrastes entre les activités de télécommunications et leur contexte plus ample, le marché du travail du secteur services et le marché de travail du Brésil, dans son ensemble. Lanalyse de la situation de l'emploi dans l'activité des télécommunications se base sur les données disponibles dans la Relation Annuelle des Informations Sociales (RAIS) du Ministère du Travail et de l'Emploi au Brésil (MTE).

Mots-CLÉs: emploi, qualité de l'emploi, restructuration du secteur des télécommunications, privatisation du secteur des télécommunications, innovations technologiques.

Daniel Gustavo Mocelin - Cientista Social, Mestre em sociologia, doutorando do Programa de Pós-graduação em Sociologia da Universidade Federal do Rio Grande do Sul. Pesquisador, desde 2002, do GP "O Trabalho na Sociedade Contemporânea”, coordenado pela Dra. Sônia Guimarães. O autor realizou estudos abordando temas como reestruturação, privatização, liberalização, competição, expansão e terceirização no setor de telecomunicações no Brasil, com ênfase especial nas implicações sociais de tais processos sobre o perfil dos empregados, as relações de emprego e a dinâmica do mercado de trabalho. Desde o ingresso no Mestrado em Sociologia, desenvolve investigações sobre a qualidade do emprego nas telecomunicações, interessado teórica e metodologicamente no tema da qualidade do emprego no contexto da sociedade da informação. 